\title{
A comprehensive review of the influence of electric field on
}

\section{flame characteristics}

\author{
Yin.Ma ${ }^{\mathrm{a}}$, Tong.Li ${ }^{\mathrm{a}}$, Jun.Yan ${ }^{\mathrm{a}}$, Xiaorong. Wang ${ }^{\mathrm{a}}$, Ji.Gao ${ }^{\mathrm{a}}$, Zuoyu. Sun ${ }^{\mathrm{b}}$ \\ ${ }^{a}$ Department of Mechanical and Engineering, JiangSu University of Science and Technology, China, \\ ${ }^{\mathrm{b}}$ Beijing Key Laboratory of Powertrain for New Energy Vehicle, Beijing Jiaotong University, China
}

\begin{abstract}
Electric field assisted combustion is an important means to improve fuel combustion efficiency. This paper conducts extensive research on flame characteristics under different forms and different application methods of electric fields, emission of soot particles and simulation status. Different flame parameter measurement methods will lead to different degrees of error, and perfect numerical simulation can make simple predictions on experimental data. Most of the current numerical simulations are in two dimensions, and it is necessary to develop a complete and accurate three-dimensional model to simulate and predict the characteristics of the flame under an electric field. The emission of soot particles is also affected by the electric field, and reasonable electric field parameters can greatly reduce the emission of soot particles. It is recommended to conduct centralized measurement of different fuels under the electric field under high pressure and temperature conditions, so as to be able to develop a wider and more accurate flame dynamics and chemical model under the electric field.
\end{abstract}

Keywords: Review; Electric Field; Ionic wind; Electric assisted combustion; Soot emission

\section{Introduction}

\subsection{Background of electric field assisted combustion}

The rapid development of science and technology and the accelerating economic globalization have made the energy problem increasingly prominent. Energy shortages, inefficient use of existing fuels, and excessive emissions of pollutants are all causes of environmental degradation. Improving the utilization efficiency of existing energy and developing alternative clean energy is the focus of current research. New combustion technologies such as electric field combustion and plasma combustion have gradually entered the public's field of vision in recent years [1-3]. The first group of scholars to study flame conductivity pointed out that during the combustion process, not only free ions but also free electrons are generated in the flame, so the electromagnetic field can influence the combustion from the outside of the flame. Recent studies have shown that the addition of electric fields can improve the efficiency of fuel combustion and effectively reduce pollutant emissions. Therefore, in-depth research and analysis of electric field-assisted combustion technology is of great significance for dealing with energy problems. 


\subsection{The importance of study electric field assisted combustion}

Electric field assisted combustion is a method of coupling the electric field with the flow field generated by the combustion flame, which changes the flame characteristics of the fuel, such as the stability of the flame, the color of the flame, the temperature of the flame, the speed of the flame propagation, and the amount of pollutants generated by the combustion, which are related to the form, intensity and application mode of the applied electric field. In 1951, calcote et al. Studied the characteristics of Bunsen flame under the condition of longitudinal electric field, and found that the electric field has a strong influence on the stability of Bunsen flame [4]. At the same time, calcote established a mechanical model of momentum transfer between positive ions and ambient air, which qualitatively explained most of the experimental results. Therefore, electric field assisted combustion has become an important method to increase combustion efficiency. However, before adding electric field to the actual combustion system, it is necessary to study and understand the combustion behavior of flame in the electric field in detail. The first step is to understand the reason why the electric field makes the flame accelerate combustion, and to characterize the flame structure and other flame characteristics through experiments and modeling, so as to make our understanding of experimental phenomena better from the perspective of chemical kinetics and physics.

\subsection{The reason why electric field can assist combustion- ion wind effect}

One of the most convincing explanations that electric fields can assist combustion is the ion wind effect. When the flame comes into contact with an externally applied electric field, due to the action of the electric field, the charge carriers are separated and accelerated toward the corresponding electrode. The electrons and negative ions move to the positively charged electrode, while the positive ions move against the inflowing fresh gas toward the edge of the grounded burner, which causes the flame to deform and shift. This is generally considered the ion wind effect. Another explanation is that the collision of accelerated electrons with neutral molecules produces free radicals. The location of free radical generation is upstream of the effective reaction zone, which increases the reactivity of the mixture. Therefore, the flame front speed has been significantly improved.

The ion wind effect can change the flame area and entrain a little air, so the flame stability will change. As long as the surrounding flame surfaces bend, the heat transfer to them will increase. The increase in flame propagation speed under the electric field is due to the increase of electron temperature in the flame front, and the increase of electron temperature reduces the adhesion rate of electrons. This will increase the concentration of electrons and the chemical activity of the electronic components in the system. When Xu et al. studied the plasma behavior in the flame, they found that the presence of an electric field would cause the flame to produce an ion wind effect, which can greatly improve the stability of the flame [5].

Generally, the ions produced in the flame zone are positive ions, so the early ion wind effect believed that the flame reaction zone produced positive ions. The positive ions would make the overall ion wind move in the direction of the cathode under the 
action of the electric field. But Park et al. used the stagnant flame method and PIV (particle image velocimetry) method to visualize the ion wind [6]. In his experiment, he observed that when the flame is on the stagnation plane, the original flow field separates near the flame, resulting in a double stagnant flow. This phenomenon shows that the ion wind actually blows negative ions to the anode and positive ions to the cathode. But due to the electric field force, the flame will be pulled towards the cathode. As shown in Figure 1, it shows the changes produced by the Bunsen flame under the action of electric field. Figure a shows the ion distribution in the flame when no electric field is applied, and figure b shows the ion distribution in the flame when an upward electric field is applied. Condition [7]. It can be seen from the figure that under the action of the electric field, the positive and negative ions in the flame move toward the negative and positive electrodes of the electric field, respectively.

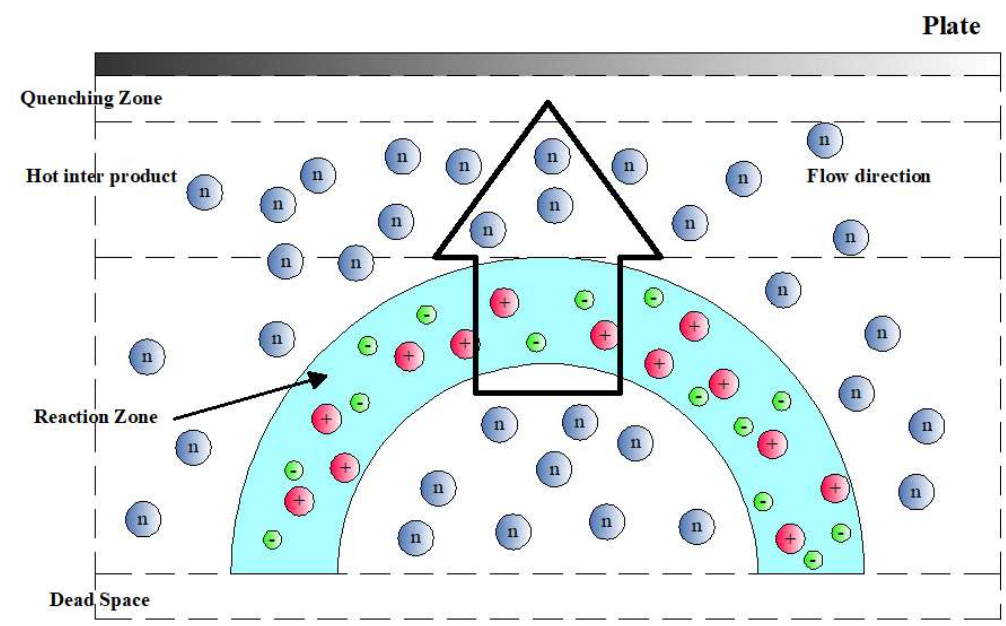

a

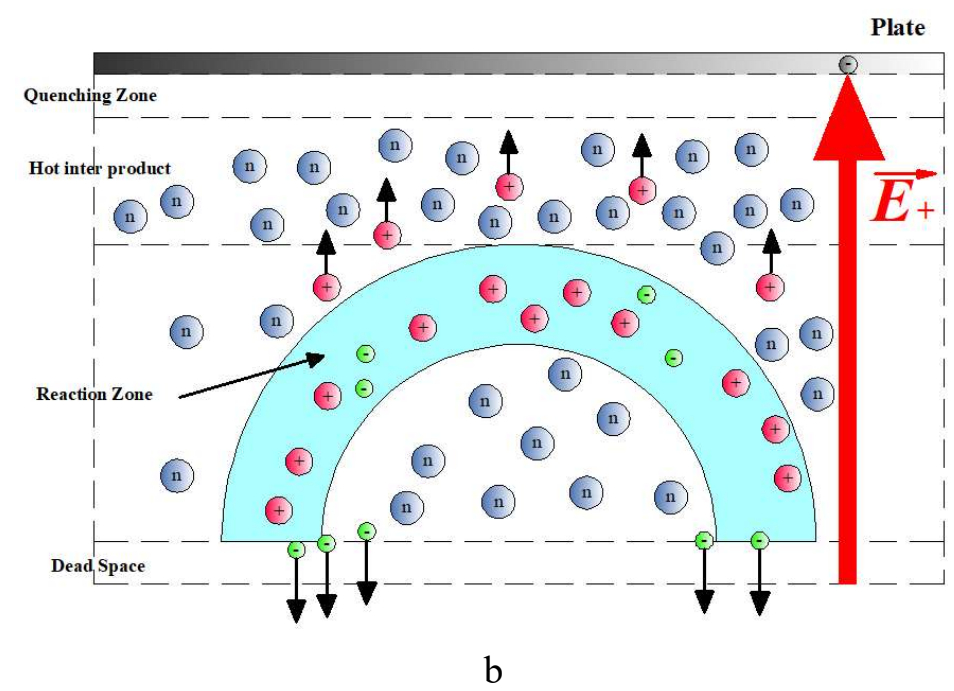

Figure 1. Schematic diagram of the influence of electric field on the position of flame ions (Figure a is the distribution of ions inside the flame when no electric field is applied, and Figure $b$ is the distribution of ions in the flame when upward electric field force is 
applied)[7]

\section{Introduction of measurement technology and its latest}

\section{development}

In recent decades of research, many experimental techniques have been proposed and developed to measure the flame-related parameters of the fuel and oxidant mixture, including Bunsen method, countercurrent/stagnation burner method, countercurrent annular groove burner method, spherical flame propagation Method and heat flux method. After adding the electric field, the measurement method is also carried out in the measurement methods that have been developed above. In this chapter, we have reviewed and introduced the latest updates of related measurement techniques used in the measurement of flame-related parameters in the electric field.

\subsection{Bunsen flame method}

The flame produced by premixing gas and air is called Bunsen flame. Combustion in which gas and air are not mixed in advance is called a diffusion flame. The Bunsen flame method is the most primitive method, and the flame that appears when burning is a cone flame. Gillon et al. used the Bunsen burner experimental device to study the response of a longer flame under a DC electric field [8]. The schematic diagram of the experimental device they used is shown in the figure 2 . A stainless steel grid is placed above the Bunsen flame, and a downstream electrode made of the grid generates a potential difference between the burners, thereby generating an electric field. Experimental studies have shown that the application of negative high voltage will cause the flame to oscillate and cause soot to burn. Positive high voltage will stabilize the flame and reduce the volume fraction of soot produced.

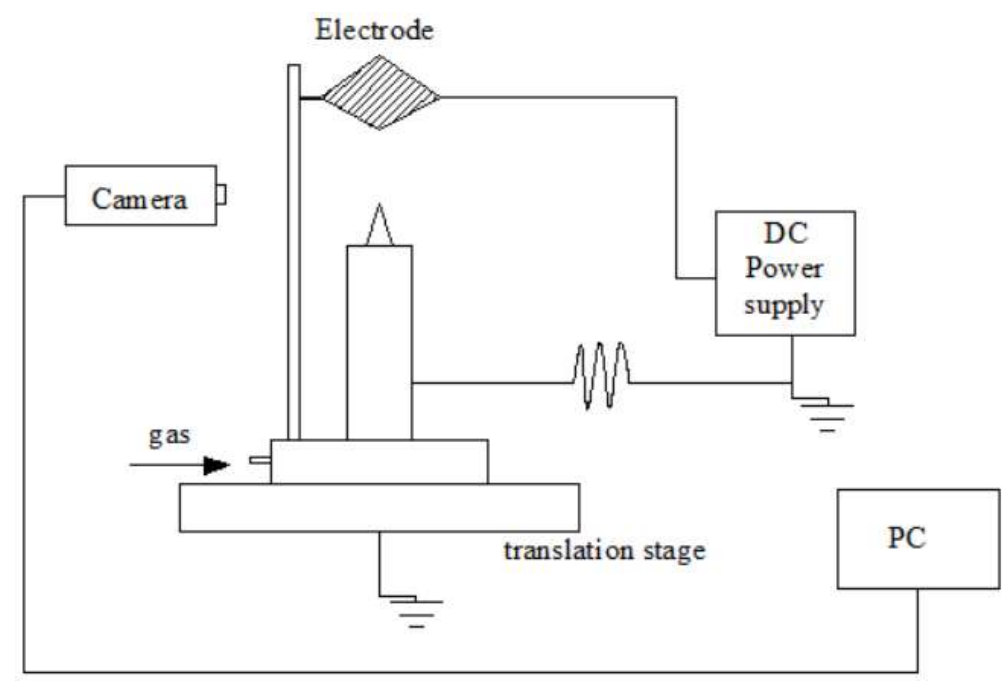

Figure 2. Schematic diagram of experimental setup of Bunsen flame under electric field [1] 
Marcum et al. and Luo et al. apply the electric field in a similar manner to the above. Two metal plates are installed above and below the flame spray device. The applied potential difference of the DC power supply between the two electrodes produces a DC electric field [9-10 ]. Experimental research found that the application of electric field increases the flame speed, and the flame length becomes shorter as the applied electric field intensity increases. This is because the electric field changes the material distribution inside the flame. This change makes the flame cells appear, which increases the flame surface area, promotes the mixing of fuel and oxidant, and increases fuel consumption and heat release per unit area. Yoon et al. and Altendorfner et al. applied an AC electric field in the original DC electric field research and used PIV and PLIF techniques to observe [11-12]. Experimental studies have shown that the addition of DC and AC reduces the speed of the flame upstream, resulting in an increase in the flame displacement speed. Experimental studies believe that the application of an electric field will only affect the flow of the flame, but will not affect the flame chemistry and free radicals.

Wang et al. grounded the burner and changed the sign of the electric field by changing the sign of the electrode applied to the plug [13]. Experimental results show that the deposition rate of soot is affected by the electric field, and is positively correlated with the negative electric field and negatively correlated with the positive electric field. But the size of the soot particles has nothing to do with the polarity of the electric field and the sign.

The Bunsen flame method is relatively old and the measurement method is simple. The flame propagation speed can be measured based on the cone flame. The premixed gas will keep moving in the Bunsen burner tube. But when using Bunsen burner to measure LBV, the flame front speed often does not match the assumption and actual measurement. The mathematics of the flame shows that there is actually a thin heating layer, and the external medium will also have a certain influence. This makes the influence of the electric field on the flame superimposed with the influence of the Bunsen flame device itself when an electric field is applied, and it becomes complicated when considering the influence of the electric field.

\subsection{Countercurrent/Stagnation Burner Method}

Stagnation flame method can obtain a stable plane flame by placing a stagnation plate. The application of stagnant flame method is more extensive, because premixed flame and diffusion flame are both measurable objects. However, the use of the stagnation plate will cause part of the flame to be transferred, so two nozzles placed in exactly the same relative position are used, and the symmetrical position of the opposing flame is the stagnant plane. There will be two symmetry on both sides of the stagnant surface. Plane flame. This kind of opposing stagnation flame is adiabatic flame, which eliminates the influence of heat loss and can minimize the influence of stretching [14]. The use of this hedging and stagnation flame method makes its measurement accuracy much higher than that of the Bunsen burner flame method.

Chien et al. used the plate stagnation flame method to study the effect of flame 
under electric field [15]. The experimental device they used is shown in Figure 3[16]. The selected material is not affected by the electric field and will not catalyze the combustion of the flame [17]. Similar to the way the Bunsen flame applies an electric field, direct current is applied above the stagnation plate and below the flame injection device, and the potential difference between the two plates forms an electric field acting on the flame. Experimental research shows that the ion wind effect produced by the application of an electric field will affect the heat distribution of the flame, especially when the plate position is just above the flame tip. Impinging Plate

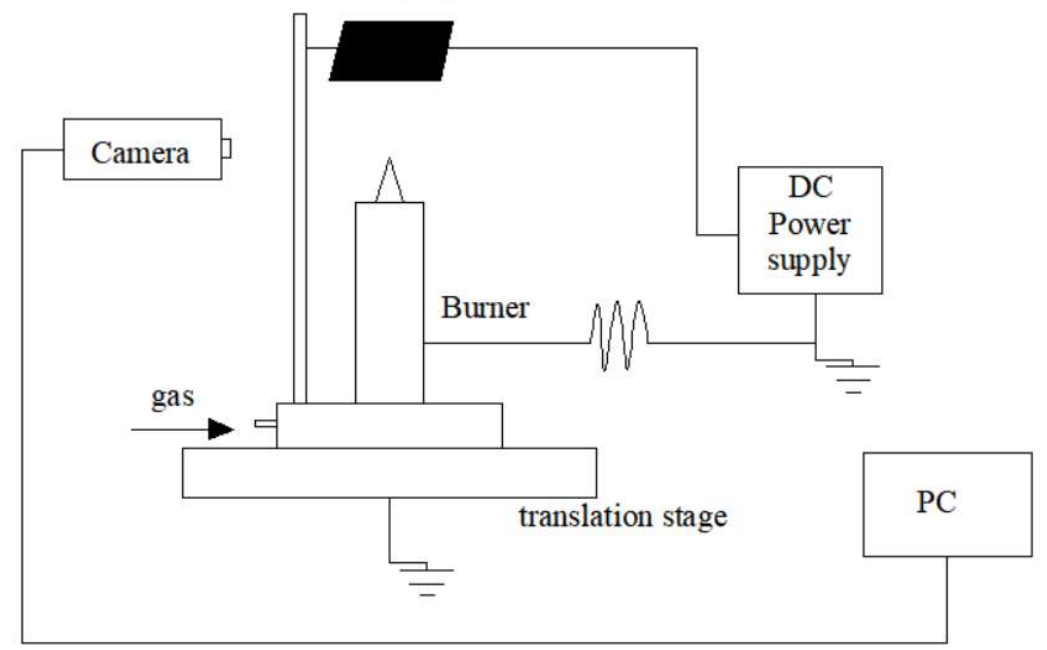

Figure 3. Schematic diagram of the experimental device for flat plate flame retardation under electric field [16]

Renzo et al. used the hedging and stagnation flame method to study the influence of flame under electric field [18]. The experimental device they used is shown in the figure 4. Two electrodes are placed at the exit of the spray device, and an electric field is generated by applying a current to the two pole plates, and the stagnant flame plane is generated at the symmetrical position of the two spray devices. The tracer particles satisfying the followability are added to the flow field. The light source illuminates the particles in the measured area in the flow field, and a high-speed camera is used to shoot. Due to the principle of laser Doppler velocity measurement, the velocity distribution of the flow field can be determined. Through experiments and simulations, Renzo et al. found that the application of an electric field produced bidirectional ion wind in the flame, the flame burning speed increased, the flame temperature rose, and the stagnation plane shifted. 


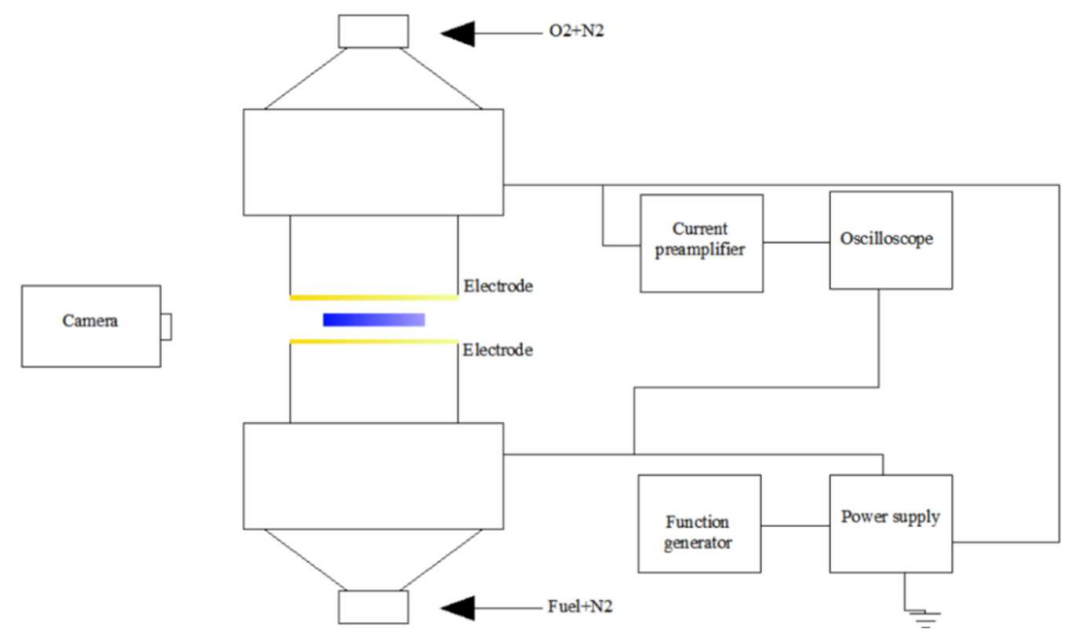

Figure 4. Schematic diagram of experimental device for opposing stagnant flame under electric field [18]

The stagnant flame method requires the use of tracer particles. The addition of tracer particles will affect the flame speed and also make the experiment more difficult. The height of the stagnant flame surface needs to be changed according to the requirements of the flame speed that needs to be measured. This approach will make the shape of the flame front unstable and the calculation of the flame stretch rate will become difficult. The biggest limitation of the stagnant flame method is that the existence of the Reynolds number makes it difficult to measure LBV under high pressure.

\subsection{Counterflow annular groove burner method}

Researchers' pursuit of adiabatic flames and unstretched flat flames led to the birth of counter-flow annular groove burners. Due to the unstable existence of Darrieus-Landau, there is no flame without stretching. Length dimension is the main factor that affects flame heat loss and stretch rate. When the flame passes through the narrow passage under the action of the electric field, due to the existence of the ion wind effect, the electric field line will be orthogonal to the direction of flame propagation [19]. The countercurrent annular groove burner can make the flame propagate in a small space, diagnose through the laser, and measure the flame displacement velocity and flow field velocity [20]. By changing the channel gap or tube diameter, find the critical LBV that minimizes the influence of the length dimension.

Manh-Vu Tran et al. used the counter-current annular groove burner method to study the effect of flame under electric field [21]. The experimental device they used is shown in the figure 5. By igniting at the designated position and blocking by the ceramic sheet, the flame spreads on one side of the groove and a trailing diffusion flame can be established [22]. A high voltage is applied to the lower part of the burner and the upper part is grounded. The electric field is applied from top to bottom by using a function generator and a power amplifier to generate a uniform vertical 
electric field in the gap of the slot.

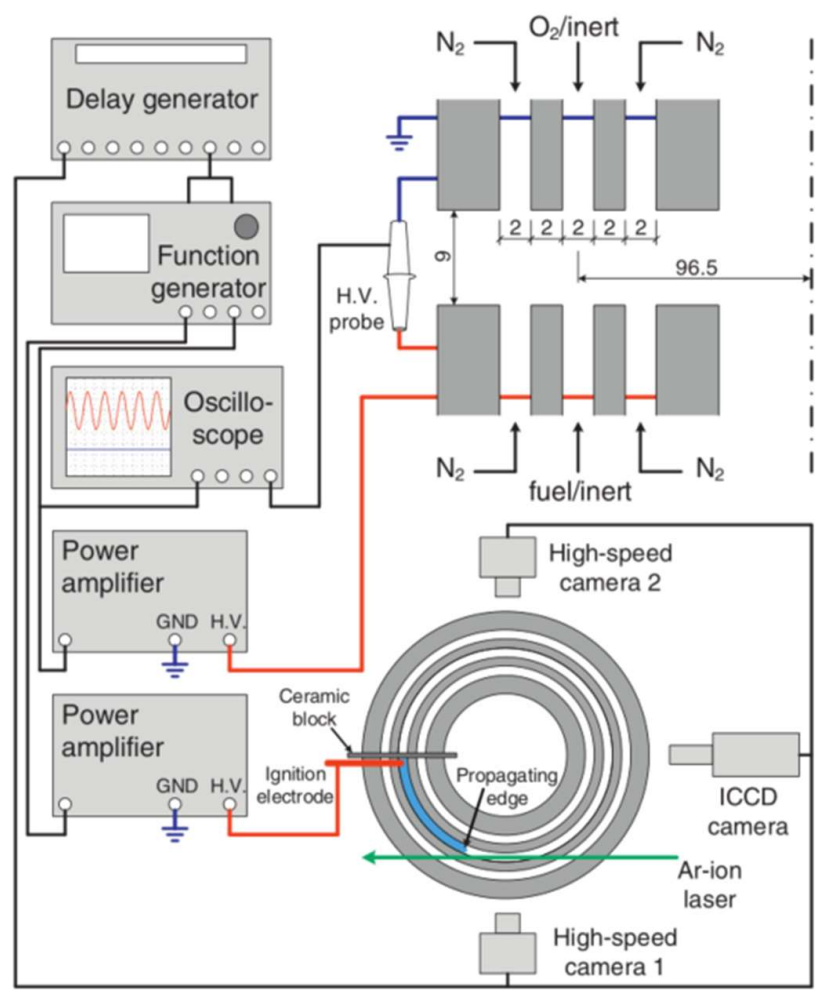

Figure 5. Schematic diagram of the experimental device of the counter-flow annular groove burner under the electric field [19]

Experimental studies have found that for premixed flames, the flame displacement velocity is inversely proportional to the voltage, and the change in frequency has little effect on the flame. The reason for this is that the main influence of flame in an electric field comes from the ion wind effect, while chemical kinetics and thermals can hardly be considered. The response of the non-premixed flame to the electric field is similar to that of the premixed flame [23]. In the case of high voltage, it can be observed through the PIV that the ionic wind moves the flame toward the cathode, and the moving speed increases with the increase of the voltage.

The use of a counter-flow annular groove burner allows the flame to be measured in a flat state. In this case, the uncertainty caused by flame stretching is reduced to a minimum. However, the measurement accuracy of the counter-flow annular groove burner under the mixture of high pressure and high combustion velocity still needs to be considered.

\subsection{Spherical flame propagation method}

In the spherical flame method, the constant-volume combustion bomb is filled with the mixture of the gas to be measured and maintained at a certain equivalence ratio, temperature and pressure. The spherical flame is ignited by the electrode at the center of the constant volume incendiary bomb, and then spreads evenly into the unignited static mixture. When the flame expands outward, it will be affected by 
flame curvature, unstable flow field, flame spread, etc. The schlieren image is captured by a high-speed camera, and the image is processed to obtain the rate of change of the flame radius, so as to calculate the unstretched LBV.

Wang et al. used the spherical flame method to study the effect of flame under electric field [24]. The experimental setup is shown in the figure 6. Two parallel and symmetrical grid electrodes are installed on both sides of the constant volume combustion bomb perpendicular to the ignition electrode. The ignition electrode forms high and low electrodes on the grid, which can generate a symmetrical electric field.

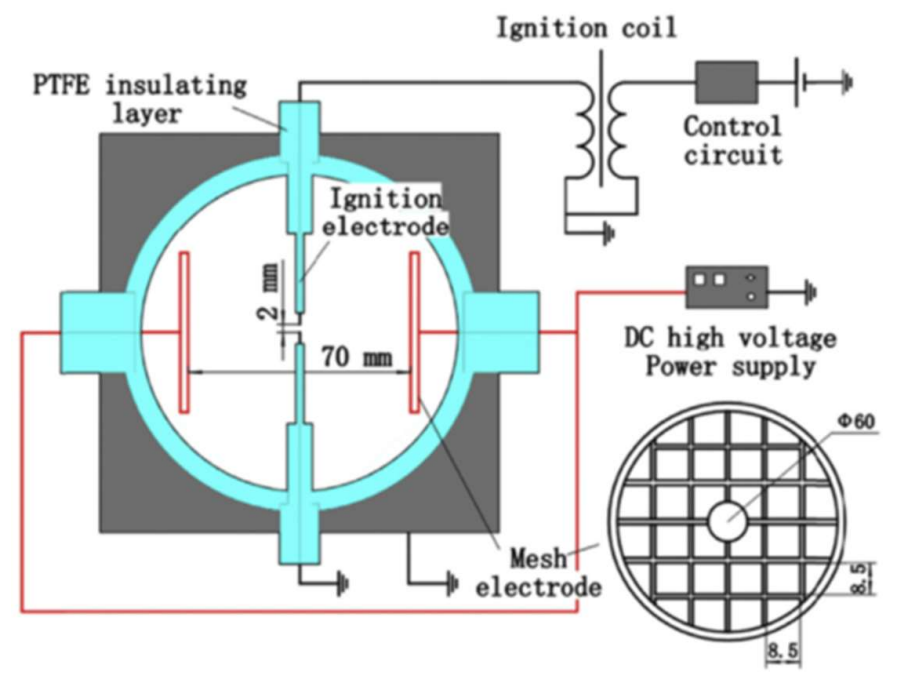

Figure 6. Schematic diagram of the experimental device of the spherical flame method under an electric field [24]

Because the flame will deform under the action of the ion wind, the flame will become an oval shape. Therefore, in order to facilitate the measurement of the flame radius change rate, the effective radius needs to be defined. As shown in the figure, Li et al. defined the effective radius of an elliptical flame [25]. The effective radius of the flame is divided into horizontal and vertical directions. From the perspective of flame curvature, plus or minus $15^{\circ}$ in the horizontal and vertical directions is defined as the effective radius. The rate of change of flame radius is divided into vertical and vertical directions for consideration, and the flame propagation velocity in these two directions is defined as $\alpha$. The experimental research of $\mathrm{Li}$ et al. found that the flame propagation speed in the horizontal direction is proportional to the voltage, and the vertical direction is inversely proportional to the voltage, and the speed under positive voltage is faster than that under negative voltage. The appearance of the ionic wind effect makes the flame surface unstable due to fluid dynamics. 


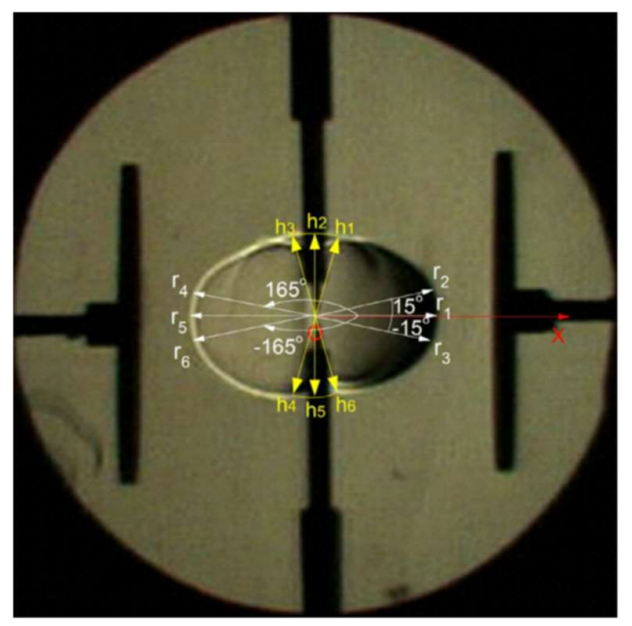

Figure 7. Definition of effective radius of spherical flame method under electric field [25]

Fang et al. and Duan et al. used similar experimental devices to study the combustion under an electric field with the spherical flame method [26-27]. Experimental studies have found that the application of voltage can increase the stretching and burning rate of the flame. When the alternating current is low frequency, the flame propagation speed will decrease, the development of ion wind will increase, and the lean combustion is greatly promoted.

The spherical flame method can well simulate the flame spread in the engine. However, if the diluted mixture is blended, the radiation absorption of the mixture may also affect the accuracy of the LBV measured by the spherical flame method. This requires further research. Different researchers use different flame non-stretching pressure zones. Most researchers believe that the flame does not exceed one-third of the bomb capacity is the constant pressure stage. This value needs to be studied to determine the precise and uniform standard.

\subsection{Heat flux method}

The heat flux method is a direct method for determining the LBV of various fuels mixed with oxidants. In this method, the flame is two-dimensional, fixed at the burner outlet, and the flow of unburned gas is perpendicular to the flame front, so the LBV is equal to the speed of unburned gas [28-29]. Its biggest advantage is that it does not require stretching correction.

Boom et al. used the heat flux method to study the effect of flame under electric field [30]. The experimental setup is shown in the figure 8 . The burner plate with small holes is connected to the burner outlet and thermocouples are added on the side. The unburned gas flowing through the burner plate compensates for the heat loss of the flame. In this case, the gas velocity is equal to the adiabatic combustion velocity. The burner acts as the negative electrode, and the electrode plate above the flame is the positive electrode. The electrode plate is energized to form a potential difference between the upper and lower electrodes, thereby applying an electric field to the flame field. Experimental studies have found that the adiabatic combustion speed is less 
affected by the electric field, and the frequency of the electric field has a linear relationship with the temperature of the adiabatic flame.

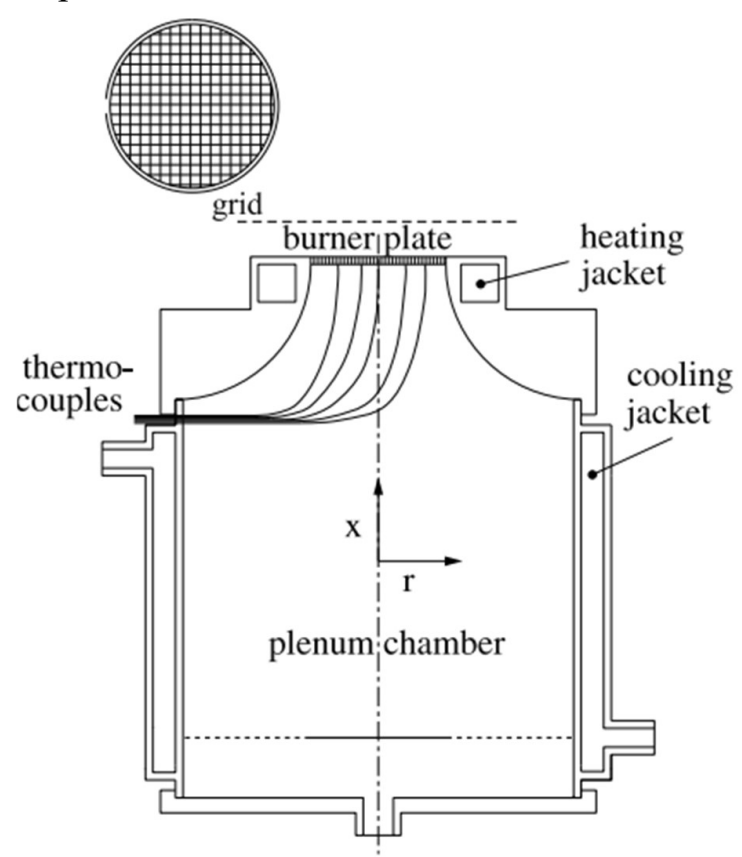

Figure 8. Schematic diagram of the experimental device of the heat flux method under an electric field [28]

The heat flux method cannot be used for mixtures with high combustion velocity. The measurement of high LBV needs to reduce the size of the hole, which will greatly increase the difficulty of making the burner. Because the higher temperature of the mixture will reduce the flame distance, this will greatly increase the difficulty of LBV measurement.

\section{Numerical analysis of premixed flame under electric field}

In the experiment of electric field assisted combustion, the most important thing is to know whether the experimental data is accurate. The advantage of the theoretical analysis method is that the results obtained are universal, and various influencing factors are clearly visible. It is the theoretical basis for guiding experimental research and verifying new numerical calculation methods. The reasonable range of the value can be predicted by numerical simulation [31]. However, it often requires abstraction and simplification of computing objects to get theoretical solutions. The experimental results obtained by the experimental measurement method are true and reliable, and it is the basis of theoretical analysis and numerical simulation. However, experiments are often limited by model size, fluid disturbance and measurement accuracy, and sometimes it may be difficult to obtain results through experimental methods. Numerical simulation can overcome the weaknesses of the first two methods. Performing specific calculations on a computer is like doing experiments on a computer. The distribution of flow field, temperature field and pressure field can be 
obtained by numerical simulation calculation [32]. In this chapter, the existing theories and the latest updates of existing related simulation technologies have been reviewed and introduced.

\subsection{Existing theories and their problems}

The existing mainstream theory for the influence of electric fields on flames is the ion wind effect, which has been introduced in detail in the previous chapters, so I won't repeat them here. Ion wind refers to the accelerated separation of ions produced by chemical ionization on the flame front under the action of an electric field. Ions collide with neutral particles in the process of acceleration and movement, and energy transfer occurs. The repeated collisions cause a large number of neutral particles to shift their directional positions. This phenomenon is called ion wind.

The ion wind effect is based on the results obtained from the stagnant flame, and does not consider the influence of the flame propagation in space on the experimental results. When in space, the collision of particles and neutrons in the flame cannot reach an equilibrium point over time like a stationary flame. Therefore, the effect of ionic wind on flame propagation is smaller than that on stagnant flame.

The influence of initial ion concentration on flame characteristics under electric field has also been studied by many scholars. The research of Vejbychristensen et al. showed that the mole fraction of ion concentration in the flame is about the order of $10^{-9} \sim 10^{-7}$ [33]. Yamashita et al. studied the ion concentration in the flame under the electric field by numerical simulation method [34]. Numerical simulation studies found that when the applied electric field is $0 \sim 9 \mathrm{kV} / \mathrm{cm}$, it corresponds to the ion unsaturated zone, $0.9-1.2 \mathrm{kV} / \mathrm{cm}$ corresponds to the ion saturation zone, and 1.2 $\mathrm{kV} / \mathrm{cm}$ above corresponds to the ion supersaturation zone. Kim et al. used numerical simulation methods to study the changing laws of ions formed near the flame zone during the combustion process [35]. By calculation, the highest ion concentration in the flame zone is about $10^{-7}$. The external electric field will cause the ions to transfer from the area with higher flame temperature to the lower temperature area. At this time, the ions have a greater influence on the reaction. Although the ionic wind effect at this time can change the position and shape of the flame surface, it has a weaker effect on the kinetics of the chemical reaction. Therefore, there are still many shortcomings in the ion wind effect, and it is necessary to develop a more complete numerical simulation model to study the influence of the electric field on the flame.

\subsection{Numerical research methods and models}

Computational fluid dynamics (CFD) is the systematic analysis of related phenomena including fluid flow, heat conduction and fuel combustion through computer numerical calculation and image display. CFD can also be regarded as a numerical simulation of flow under the control of basic fluid equations (mass conservation equation, momentum conservation equation, energy conservation equation). Through this kind of numerical simulation, the distribution of basic physical quantities (such as speed, pressure, temperature, concentration, etc.) at various positions in the flow field of extremely complex problems can be solved. The 
overall working process of the numerical simulation is shown in the figure 9.

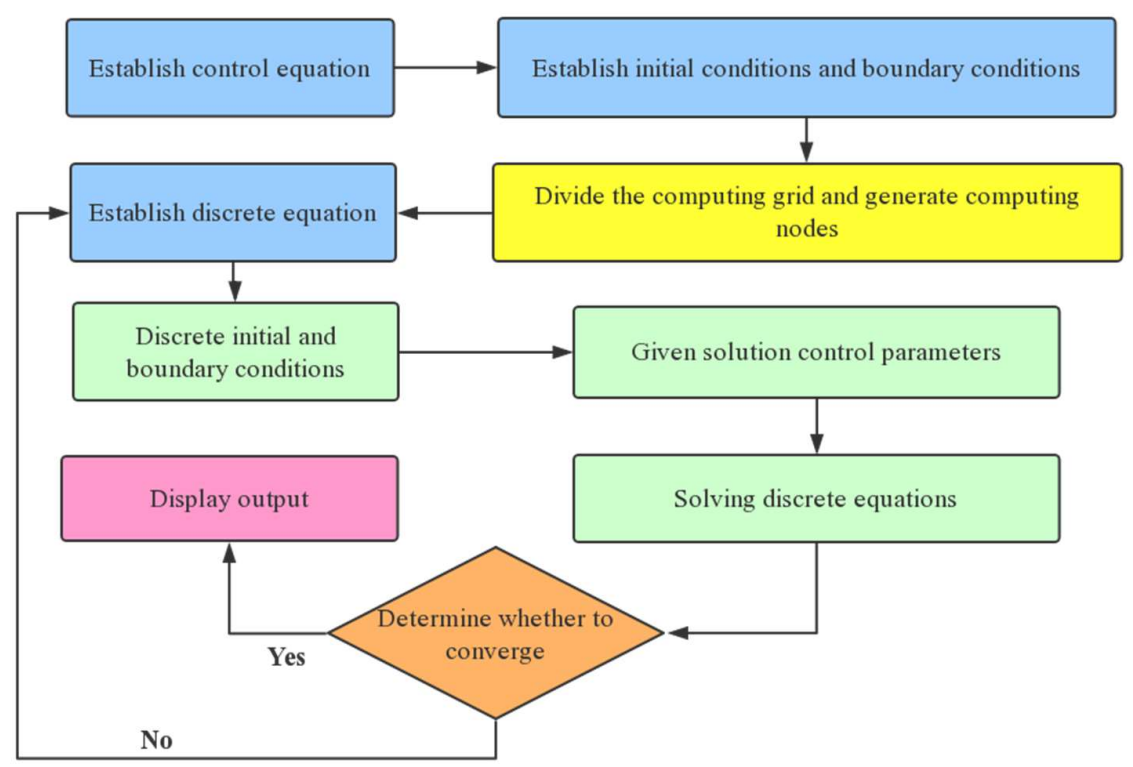

Figure 9. General process diagram of numerical simulation

\subsubsection{One-dimensional model}

One-dimensional numerical simulation has the advantages of simple modeling and accurate simulation when studying the electric field's ability to enhance combustion by acting on the ions present in the flame. When using a one-dimensional model to verify this phenomenon, it often takes less time than two-dimensional and three-dimensional models.

The two-step chain branching chemical model originally developed by Zeldovich et al. improved the one-step model [36]. In later research, Dold et al. made some modifications to the recombination steps of free radicals, so that the chain branching reaction can remain stable at a crossover temperature [37-38]. The chain branching reaction is usually located in the high temperature area of the flame, and the intermediate species or chemical radicals of the reaction diffuse in the upstream and downstream of the thin chain branching area and terminate the reaction through a very exothermic chain. Sharpe et al. believe that the two-step kinetic model optimized by Dold et al. is a better method than the single-step model. This model is more accurate and realistic in describing hydrocarbons and hydrogen flames [39].

Sa'nchez-Sanz et al. combined two additional reactions to illustrate the generation and consumption of charged species, thus supplementing the model proposed by Dold [40]. The table shows the reaction formula used by Sa'nchez-Sanz et al. to simulate the influence of the electric field in the premixed flame.

Table 1.Chain branching, chemical ionization and dissociation complex reactions used 
by Sa'nchez-Sanz et al. [40]

\begin{tabular}{|c|c|c|}
\hline$i_{S D}$ & Reaction & \\
\hline I & $F+Z \rightarrow 2 Z$ & $\Omega_{I}=A_{I} \frac{\rho^{2}}{W_{F} W_{Z}} Y_{Z}^{\prime} Y_{F}^{\prime} \exp \left(-E_{I} / R T\right)$ \\
\hline II & $Z+M \rightarrow P+M+q_{I I}$ & $\Omega_{I I}=A_{I I} \frac{\rho^{2}}{W_{Z} \bar{W}} Y_{Z}^{\prime}$ \\
\hline III & $Z+M \rightarrow Z^{+}+e^{-}+M$ & $\Omega_{I I I}=A_{I I I} \frac{\rho^{2}}{W_{Z} \bar{W}} Y_{Z}^{\prime} \exp \left(-E_{I I I} / R T\right)$ \\
\hline IV & $Z^{+}+e^{-} \rightarrow P+q_{I V}$ & $\Omega_{I V}=A_{I V} \frac{\rho^{2}}{W_{Z^{+}} W_{e^{-}}} Y_{Z^{+}}^{\prime} Y_{e}^{\prime}$ \\
\hline
\end{tabular}

Among them, $\mathrm{F}$ is fuel, $\mathrm{T}$ is temperature, $\mathrm{Z}$ is neutral radical, $\mathrm{Z}+$ is positive radical, e- is electron, $\Omega$ is reaction rate, $\rho$ is mixture density, $\mathrm{W}$ is molecular weight, $\mathrm{q}$ is heat of reaction, and Y'is mass fraction. Reactions I and II replicate the model proposed by Dold, respectively, while reactions III and IV simulate the theory first proposed by Calcote et al. and used in many numerical studies of chemical ionization and dissociation recombination [41-43].

The one-dimensional simulation results of Sa'nchez-Sanz et al. showed that the application of the external electric field $\mathrm{E}_{0}$ caused some changes in the distribution of protons and electrons around the thin chain branch layer. This change increased the rate of heat release and made the flame speed also Change accordingly. The specific explanation for this phenomenon is that when the temperature of the electric field is high enough to overcome the activation energy of reaction III, the positive electric field $\mathrm{E}_{0}$ can promote the accumulation of electrons in the cold area of the flame, and the availability of electrons to react with protons through reaction IV is also Got an increase. When $\mathrm{E}_{0}<0$, the opposite effect is observed.

The one-dimensional model cannot be used for quantitative prediction, but can only help researchers to increase their understanding of the phenomenon. By adding some principles such as thermal expansion, fluid dynamics or chemical dynamics into the simulation, it is the basis for reducing modeling workload and building abstract models.

\subsubsection{Two-dimensional model}

Two-dimensional numerical simulation has the advantages of fewer grids and fast calculation speed. Scholars mostly concentrate on two-dimensional simulation on numerical simulation research of combustion mechanism. Two-dimensional simulation considers more things than one-dimensional simulation. But two-dimensional simulation will also simplify things for computational efficiency. For example, when building a two-dimensional model, for the addition of the flame front 
energy source term, a simplified method of uniform addition without distinguishing species will be used to simulate the influence of electric field force and electromagnetic field energy on ions in the flame front.

The simulation of aerodynamic and thermal effects in two-dimensional numerical simulation is generally realized by user-defined functions (UDF). Adding a power source term in the $\mathrm{x}$ direction to a specific particle in the Navier-Stokes (N-S) equation is the most common method. The general formula of Navier-Stokes momentum conservation equation along the $\mathrm{x}$ direction is:

$\rho \frac{D u}{D t}=k_{x}-\frac{\partial p}{\partial x}+\frac{\partial}{\partial x}\left[\mu\left(2 \frac{\partial u}{\partial x}-\frac{2}{3} \nabla \bullet V\right)\right]+\frac{\partial}{\partial y}\left[\mu\left(\frac{\partial u}{\partial y}+\frac{\partial v}{\partial y}\right)\right]+\frac{\partial}{\partial z}\left[\mu\left(\frac{\partial w}{\partial x}+\frac{\partial u}{\partial z}\right)\right]+\dot{O}$

Where $\mathrm{u}, \mathrm{v}$, and $\mathrm{w}$ are the components of the vector velocity $\mathrm{V}$ in the $\mathrm{x}, \mathrm{y}$, and $\mathrm{z}$ directions; $\mathrm{kx}, \mathrm{ky}$, and $\mathrm{kz}$ are the components of the volume force acting on the unit mass fluid in the $x, y$, and $z$ directions respectively; $p$ is the pressure $; \rho$ is density; $\mu$ is dynamic viscosity; $\mathrm{t}$ is time;

$$
\frac{D}{D t}=\frac{\partial}{\partial t}+u \frac{\partial}{\partial x}+v \frac{\partial}{\partial y}+w \frac{\partial}{\partial z} ; \quad \nabla \bullet V=\frac{\partial u}{\partial x}+\frac{\partial v}{\partial y}+\frac{\partial w}{\partial z}
$$

$\dot{O}_{\text {is }}$ the energy source term added to the numerical formula. According to the difference of DC and AC, the expression is also different. When the simulation is direct current, the expression is as follows:

$$
\dot{O}=\left\{\begin{array}{l}
F_{\text {const }},(500 K \leq T \leq 1600 K) \\
0,(T<550 K, \quad T>1600 K)
\end{array}\right.
$$

When the simulated alternating current, the expression is as follows:

$$
\dot{O}=\left\{\begin{array}{c}
2^{1 / 2} F_{\text {const }} \sin (2 \pi \omega t),(500 K \leq T \leq 1600 K) \\
0,(T<550 K, \quad T>1600 K)
\end{array}\right.
$$

Among them, $\mathrm{F}_{\text {const }}$ is the effective value of the alternating volume force, and $\omega$

is the alternating frequency.

The electromagnetic heating effect is realized by adding an energy source term to a specific particle in the N-S equation. The general formula of the energy conservation equation of the $\mathrm{N}-\mathrm{S}$ equation is:

$$
\begin{aligned}
& \frac{\partial e}{\partial t}+u \frac{\partial e}{\partial x}+v \frac{\partial e}{\partial y}+w \frac{\partial e}{\partial z}=\frac{\partial}{\partial x}\left(\lambda \frac{\partial T}{\partial x}\right)+\frac{\partial}{\partial y}\left(\lambda \frac{\partial T}{\partial y}\right)+\frac{\partial}{\partial z}\left(\lambda \frac{\partial T}{\partial z}\right)- \\
& p(\nabla \bullet \vec{v})+\vec{k} \bullet \vec{v}+\rho \bullet \dot{q}_{s}+\mu \bullet \Phi+\dot{E}
\end{aligned}
$$

Among them $\dot{E}$,is the added energy source term, and its expression is: 


$$
\dot{E}=\left\{\begin{array}{l}
f(r),(550 K \leq T \leq 1600 K) \\
0,(T<550 K, \quad T>1600 K)
\end{array}\right.
$$

Hu et al. simplified some of the conditions to be considered when building a two-dimensional model of the influence of the electric field on the flame [44]. In their model, the transport equations of ions and electrons are not considered at the same time, and the electric field is considered to be an ideal stable electric field. Papac and Dunn-Rankin studied the effects of ion diffusion and particle migration on ion wind [45]. When they built the model, they simplified some conditions so that the flame could remain stable at the exit.

In order to verify the existing experimental conclusions, Belhi et al. built several two-dimensional models to verify [46]. The results show that if only the influence of chemical kinetics is considered, the ion density in the flame will eventually stabilize. If only the influence of ion wind is considered, then the existence of ion wind improves the stability of the flame. This is consistent with the previous experimental conclusions.

The migration of ions and particles under the electric field has an important influence on the effect of the electric field on the flame, and all needs to be considered. The constant value assumption used in most numerical simulations and the establishment of the relationship between the mixture composition and temperature need to be improved. The simulation modeling of the influence of negative ions needs to be further developed and studied, especially when the reverse potential is applied.

\subsubsection{Three-dimensional model}

Although one-dimensional and two-dimensional models can provide qualitative physical and chemical explanations for the phenomenon of flames under electric fields, the effects of some electron migration processes and ionization phenomena in the flame combustion process have not been established to illustrate the role of a complete model. In particular, the simulation of flame phenomena under the action of negative charges requires further research. The construction of a three-dimensional model can make the flame's response to the electric field more clearly presented, but this requires high-quality electron migration and chemical models to accurately predict the spatial distribution of electrons and related ions [47-48]. The problem of the three-dimensional model lies in the huge amount of calculation and the reduction of calculation efficiency. If the drift speed of electrons is taken into account, it will further increase the burden on the computer [49]. Therefore, it is necessary to simplify certain chemical effects in the three-dimensional model [50]. For example, it is difficult to accurately describe the multi-component transport coefficient in a multi-dimensional problem. Using a constant Lewis number is a choice to improve calculation efficiency.

By using the model framework developed by the team in the past few years, Belhi has studied and built a complete unsteady three-dimensional flame response model of methane-air under a transverse electric field [51-53]. The model completely simulates the ion wind effect and proves it. This model integrates the previously built 
models and considers a variety of factors. From the aspect of electric field, the hydrodynamic influence of electromotive force, the influence of ohmic heating, the influence of substance diffusion, and the migration of electrons and ions need to be considered. Inside. The simulation results are consistent with the experimental results, which is very useful for improving the ionization mechanism. There are still some differences between experiments and model predictions, and further research is needed to improve the mechanism. The establishment of the three-dimensional model can continue to be improved, for example, the detailed comparison of different DC and $\mathrm{AC}$ electric fields under sub-saturation can be studied [54].

\subsection{Compare the predictions of different models}

One-dimensional model can be built by adding simple combustion mechanism and electric field influence mechanism. The one-dimensional model cannot be used for quantitative measurement, but can only be used to increase researchers' understanding of the phenomenon of flame burning in an electric field.

Two-dimensional models can be built by coupling the electric field and the combustion field and adding some more complex UDFs. A two-dimensional model can be quantitatively measured, but the model will be simplified when it is built, and the factors considered will be incomplete. When the lateral ion wind adds momentum to the main flow, additional momentum needs to be added from the surrounding environment, resulting in entrained flow in the $\mathrm{z}$ direction. Two-dimensional modeling cannot capture the three-dimensional effects caused by these entrained flows.

A three-dimensional model can be built by considering the existing influencing factors and mechanisms thoroughly and simplifying and ignoring some of the less influential factors. The 3D simulation model is complicated to build and takes a long time to calculate. It considers a full range of influencing factors, and can accurately and quantitatively measure the various values of the flame in the electric field. And can verify and improve the existing flame burning mechanism in the electric field.

\section{The influence of different electric field distribution forms on the flame}

Different forms of electric field application will have a certain impact on the characteristics of the flame. According to whether the electric field direction is parallel and perpendicular to the flame direction, the electric field can be divided into vertical electric field, horizontal electric field and single electrode electric field; according to whether the electric field is evenly distributed, it can be divided into uniform electric field and non-uniform electric field; generally speaking, a uniform electric field is used The characteristics of combustion flame are mainly studied by non-uniform electric field. In the following, the recent research progress of electric field and combustion flame characteristics will be explained from the vertical electric field, horizontal electric field and single-electrode electric field.

\subsection{Vertical electric field}


When using a vertical electric field, when the direction of the applied electric field force is opposite to the direction of the thermal buoyancy experienced by the flame burning, the droplet can reach a state of approximate equilibrium. Using this principle, the flame under microgravity can be simulated. Burning phenomenon. Osamu et al. studied the combustion behavior of a single droplet in a vertical DC electric field [55]. Experiments have found that the minimum combustion rate constant is greater than the minimum combustion rate constant under microgravity. This indicates that the droplet is under microgravity and not completely weightless.

Ueda et al. studied the combustion of a single droplet in a microgravity environment under a vertical DC electric field [56]. Experimental research found that flame deformation and combustion rate constant increase with the increase of electric field intensity. It is also observed that the degree of influence of the electric field is affected by the characteristics of the fuel soot. Okajima et al. studied the effect of buoyancy on droplet combustion [57]. Research suggests that the behavior of a single droplet in the accelerated fall of the flame and hot gas area is not much different from the behavior under normal gravity conditions.

Imamura et al. also studied the relationship between the voltage applied to the vertical electric field and the electrode distance when the flame is vertically symmetrical [58]. Experiments have found that the degree of flame deformation is a function of voltage and 1.5 times the electrode distance. Under different voltages, combustion rate and combustion products will have a great influence. When the voltage continues to increase to break down the air, the amount of combustion products such as $\mathrm{CO}$ and $\mathrm{NO}$ will increase.

For the vertical electric field, when the direction of the electric field force is opposite to the direction of the buoyancy of the flame, the flame burning under microgravity can be studied. But under the condition of vertical electric field, the influence of electric field intensity on flame is not obvious.

\subsection{Lateral electric field}

When a transverse electric field is applied, the flame characteristics respond better to the intensity of the received electric field. The force in the vertical direction of the flame is small, so the flame of the transverse electric field stretches obviously in the horizontal direction, but the stretch in the vertical direction is very small. , Even being restrained from stretching. Cha et al. used DBD (dielectric barrier discharge) to study the combustion characteristics of flames in a transverse electric field [59]. Experiments have found that there is a critical electric field strength in the transverse electric field. When the critical electric field strength is reached, the air can be in a breakdown state to form a plasma electric field. In this case, the electric field can change the flame shape (such as height reduction) and color. This shows that DBD's low-temperature plasma technology can control the height of the flame and the concentration of soot particles.

$\mathrm{Li}$ et al. placed mesh-shaped electrodes with an outer diameter of $60 \mathrm{~mm}$ symmetrically in the lateral direction to realize the application of a lateral electric field [60]. In the experiment, the mesh electrode was negatively energized, and the 
ignition electrode was connected to the ground to realize the application of electric field. The experiment considers that when the electric field strength reaches a certain level, air breakdown will occur [61]. In order to avoid this situation, a complicated mechanism should be considered, so the voltage applied in the experiment did not exceed the critical value of the voltage that can break down the air. Experimental studies have found that the transmission of free radicals is affected by ion driving, so in the direction of the electric field, the flame displacement speed increases, and the speed perpendicular to the electric field direction is suppressed. With the increase of voltage, the instability of the fluid dynamics of the flame becomes more obvious, the peak pressure of the flame increases, and the flame start time decreases.

The low-temperature non-equilibrium plasma generated by the DBD transverse electric field can be used to support the combustion of low-calorific value fuels to achieve stable flame combustion. The transverse electric field causes the flame to be stretched in the horizontal direction and suppressed in the vertical direction. At the same time, the electric field strength of the transverse electric field has an obvious effect on combustion, and when the angle of the applied electric field changes, the combustion will also be affected, but there is a lack of quantitative research in this area.

\subsection{Unipolar electric field}

The unipolar electric field is the divergent electric field. Researchers mainly consider the influence of the electric field on the flame characteristics from the aspect of the frequency of the applied electric field. Ryu et al. used a single-electrode electric field to study the oscillation behavior of lift flames at low frequencies [62]. Three different types of oscillating flames were observed. (1) Small-scale large-scale oscillation independent of the applied frequency; (2) Small-scale oscillation synchronized with the applied frequency; (3) Double-period coupled oscillation embedded in the small-scale oscillation in the large-scale oscillation. Ryu et al. analyzed that the reason for the flame oscillation at multiple scales is the instability of combustion, and the ion wind generated by the application of the electric field promotes this oscillation. But the experiment did not consider the influence of fire source power, and the fire source power range used in the experiment was small.

Kim et al. used a fixed single-electrode device to study the rising speed and stability of the propane jet flame [63]. Experiments have found that the stability will be improved in a low-voltage AC electric field, but the electric field under high voltage affects the stability of the flame, and the suspended speed decreases. The fire source power range studied in the experiment is smaller, and a larger power range is needed.

Under the electric field generated by a single electrode, the relationship between the multi-scale oscillation of the flame and the frequency of the electric field is a mechanism that experimenters need to explore. The research on the single-click electric field lacks experimental technical means for further verification, and also lacks research in a larger combustion power range. 


\section{The influence of different electric field application methods on flame}

There are many controllable variables in the electric field, such as DC electric field or AC electric field, the sign of the electric field, the frequency of the electric field and the intensity of the electric field. In the past, many studies have been conducted in these directions and some conclusions have been drawn. In this chapter, the existing research conclusions have been reviewed and introduced.

\subsection{Types of electric field}

The type of applied electric field is divided into direct current electric field and alternating current electric field. Direct current can be regarded as zero-frequency alternating current. Under the action of DC electric field, continuous ion wind will be formed in the flame, but under the action of AC electric field, the effect of ion wind is not continuous [64]. This makes the influence of DC electric field and AC electric field on flames inherently different [65]. Won et al. studied the influence of DC electric field on the stability of propane flame [66]. The experimental results show that the DC electric field has a smaller effect than the AC electric field. The numerical simulation of $\mathrm{Li}$ et al. showed that under the DC electric field, the ion wind effect is the dominant effect affecting the flame [67]. In an AC electric field, at low frequency, similar to a DC electric field, the main factor that affects is the two-way ion wind. Under high frequency AC electric field, the main factor that affects the flame is the electrochemical effect.

The application of a high voltage DC electric field will make the flame tend to extinguish. Under the action of a high-voltage AC electric field, the heat and mass transfer effect between the unignited area and the flame front will increase, and the combustion rate will increase. The application of an electric field will make the appearance of flames in different flows unstable [68]. Gan et al. studied the behavior of ethanol flame under a DC electric field [69]. Experiments have observed that the evaporation rate of ethanol is much slower than the rate of increase of the combustion rate caused by the ion wind effect, so the application of a direct current electric field reduces the range of stable flame operation.

Simeni et al. used Bunsen burner to study the influence of hydrogen diffusion flame in AC electric field [70]. Experimental studies have shown that the ion wind effect makes the flame present a symmetrical geometric shape during the diffusion process, and generates an offset electric field in the plasma flame. The particle flow in the flame makes the deformation of the flame the dominant cause. However, when the electrode gap is reduced and the flow rate of the introduced gas is too fast, the ion wind effect will be reduced. ATA et al. studied the possibility of improving the stability of thin flames by applying a DC electric field to an inverted cone flame [71]. The experimental results found that when the flow rate of the gas introduced increases, the effect of the electric field in stabilizing the flame combustion will be greatly reduced.

\subsection{The sign of the electric field}


The difference in the sign of the applied electric field will cause the sign of the ion wind effect in the flame to change. The generation mechanism of positive ion wind and negative ion is different, and the effect on flame is also different. Zhen et al. used the plate stagnation flame method and applied voltage to the stagnation plate to study the effect of ion wind on the heat transfer of flame impact [72]. Experimental phenomena show that the application of a forward electric field can make the flame more stable. When the magnetic field reverses, the flame tends to blow away.

The cause of positive ions is chemical reaction, and the cause of negative ions is the adsorption of electrons and neutral molecules [73]. Therefore, when the positive ion wind develops to the later stage, the vortex that hinders the reaction will be formed in the flame front, which reduces the promotion effect of the flame. However, the ion wind effect of the positive ion wind generated by the application of a negative electric field is stronger, and it has a greater promotion effect on the flame before the vortex that inhibits the development appears in the later stage [74]. Eugene et al. experimentally studied the response of a premixed methane flame in a DC electric field [75]. Experiments have observed that when the flame is subjected to a positive electric field and a negative electric field, it deforms due to the effect of the ion wind, and as the flow velocity increases, the degree of deformation decreases. When the negative ion wind generated by the application of a positive electric field develops to the later stage, the flame is stretched into a shuttle shape, which is a horizontal force, and the promotion effect of the flame will become more and more obvious. Sakhrieh et al. studied the flame response at high pressure by applying a DC electric field [76]. The experimental results show that under the positive voltage, the higher the pressure, the more obvious the influence of the electric field, and there is no suppression similar to the positive ion wind in the later stage. Therefore, the ion wind effect produced by the negative electric field is more obvious, and the positive electric field can better promote the flame combustion.

\subsection{Frequency of electric field}

The aerodynamic effect and electrochemical reaction are the main factors that the electric field affects the flame, and the $\mathrm{AC}$ electric field has the best frequency for the influence of the flame aerodynamic effect and electrochemistry. It is necessary to obtain the frequency with the best combustion-supporting effect through continuous experimentation and exploration.

\subsubsection{Low-frequency AC electric field combustion-supporting analysis}

In low-frequency electric fields, aerodynamic and thermal effects are the main reasons to promote combustion. The change of flame combustion characteristics depends on which effect is dominant [77]. Bidirectional ion wind is the main mechanism of low-frequency electric field in the electric field for combustion-supporting [78]. However, the development of ion wind will be affected by the vortex in the later stage, which will gradually reduce the combustion-supporting effect on the flame [79]. After the particles in the flame migrate, the uneven concentration will also lead to the weakening of the influence of 
the electric field on the flame. Park et al. used the hedging stagnation flame method to study the influence of AC electric field on non-premixed flame [80]. The experimental results show that the application of AC electric field makes bidirectional ion wind and oscillation in the flame, and the flame has different response states at low frequency and high frequency. When the frequency is low, the flame oscillation amplitude is stable, and when the frequency is high, the flame amplitude decreases due to the decrease of the charge density in the flame.

The combustion-supporting effect of the low-frequency electric field on the flame increases as the frequency decreases [81]. Kim et al. studied the effect of AC electric field on methane flame separation speed through Bunsen flame [82]. It has been observed that the AC electric field is positively correlated with the flame separation speed. Subsequently, Kim et al. studied the influence of the application of AC electric field on the stability of premixed flame through Bunsen flame [83]. Experimental results show that low-frequency AC makes the flame unstable when the blowing speed drops. The dual ion wind effect makes the flame change non-monotonously when the blowing speed is AC frequency.

\subsubsection{High-frequency electric field combustion analysis}

In high-frequency electric fields, electrons are the main reason for promoting combustion. Electrons change from low-frequency vibration to high-frequency vibration through collision to obtain higher kinetic energy. The high frequency vibration of the electrons causes the flame to produce a thermal effect, thereby increasing the flame propagation speed, the burning rate and the fuel reaction rate.

The combustion mechanism of high frequency electric field for flame is different from that of low frequency. Electrochemical reaction is the main mechanism of electric field and high frequency electric field to support combustion. The electromagnetic energy provided by the high-frequency electric field can make the energy level of the oxidant reach a threshold and the excitation can reach a higher energy level, which can accelerate the chemical rate of the flame in the reaction process, thereby achieving the effect of combustion.

The combustion-supporting effect of high-frequency electric field is better than that of low-frequency electric field. The flame in the high-frequency electric field is stretched due to the non-uniformity of the input electromagnetic energy, and the stretching amplitude is positively related to the frequency. In the high-frequency electric field, when the frequency increases, the better the electric field promotes the flame, the combustion pressure and the average flame propagation speed will also increase, which is different from the low-frequency AC electric field.

The 3D simulation of Ansoft Maxwell software can quantitatively study the electric field intensity generated by high-voltage electrodes of different sizes and structures. However, the simulation of the electric field by Ansoft Maxwell software is an electrostatic simulation before combustion. Due to the complexity of the combustion process, it is currently impossible to simulate the electric field distribution during the combustion process, and further research is needed in the future.

\subsection{Electric field strength}


The higher the electric field strength, the greater the deformation of the flame. When the applied voltage is large enough, the electric field will be broken down by flame discharge. At this breakdown voltage, high-temperature combustion products with conductive properties that occupy part of the electrode space will generate arcs. Tretyakov et al. studied and analyzed the influence of weak electric field and laser radiation on the combustion of hydrocarbon mixtures [84]. In the experimental study, a periodic pulsating electric field is used to prevent the flame from being broken down due to excessive voltage. Experimental research results show that the application of periodic electric field improves the combustion limit and combustion rate of the flame.

Duan et al. studied the influence of electric field intensity and electric field distribution on the flame by applying a DC electric field to the flame of a mixture of $\mathrm{CH} 4$ and air nitrogen [85]. The experimental results show that the increase of the electric field intensity will lead to the increase of the flame propagation speed and present a linear correlation. Therefore, the uniform electric field is better than the uneven electric field in promoting the flame propagation speed. Kuhl et al. used PLIF observation to study the effect of weak electric field on premixed flame [86]. The experimental results show that as the electric field intensity increases, the flame oscillation time gradually decreases. In subsequent studies, Kuhl et al. studied the influence of electric field strength on flame temperature changes [87]. The experimental results show that the increase of the electric field intensity increases the intensity of the ion wind, which causes the flame temperature to rise.

The intensity and distribution of the electric field play an important role in the promotion of lean combustion, and more research on the combustion of different mixtures is needed. The mechanism of combustion in a weak electric field is still lacking.

\section{The influence of the application of electric field on the soot particles in the flame}

The flame is a plasma, so when an electric field acts on the flame, the flame and the soot particles produced will also be affected. Therefore, many researchers have tried to study the charging characteristics of particles and the influence on their own formation and agglomeration by artificially increasing the influence of electric field force in the past 50 years. It can be seen from the table that with the continuous development of science and technology, the research content of researchers is getting deeper and deeper. As shown in Table 2, it summarizes the research history of the charging characteristics of soot particles and the influence of electric field from 1950s to the past ten years. A large amount of soot particles will affect people and nature, so it is very important to study the influence of electric field on the emission of soot particles in flames. It can be clearly seen from the table that the experimental methods are continuously improving, and the research direction is also constantly deepening. In this chapter, the latest updates of existing diagnostic techniques and related achievements have been reviewed and introduced. 
Table 2. The charging characteristics of soot particles and the research process affected by the electric field.

\begin{tabular}{|c|c|c|c|c|}
\hline Years & $\begin{array}{l}\text { Representative } \\
\text { person }\end{array}$ & Research direction & Experimental method & Conclusion \\
\hline $1950 \mathrm{~s} \sim 60 \mathrm{~s}$ & Sugden;Thrush[88] & $\begin{array}{l}\text { Nanoparticles and } \\
\text { Nanotubes }\end{array}$ & Scanning electron microscope & Soot particles in the flame are charged \\
\hline $1960 \mathrm{~s} \sim 70 \mathrm{~s}$ & Weinberg[89] & $\begin{array}{l}\text { Soot particle growth } \\
\text { process }\end{array}$ & Scanning electron microscope & $\begin{array}{l}\text { The growth of soot is related to the charged } \\
\text { components in the flame; the voltage and } \\
\text { current have a linear relationship }\end{array}$ \\
\hline \multirow[t]{2}{*}{$1970 \mathrm{~s} \sim 80 \mathrm{~s}$} & Calcote[90]; & $\begin{array}{l}\text { Charge number of soot } \\
\text { particles in flame }\end{array}$ & $\begin{array}{l}\text { the relationship between voltage } \\
\text { and current; }\end{array}$ & $\begin{array}{c}\text { The particles in the flame generally can } \\
\text { only charge } 1 \text { to } 2 \text { electrons }\end{array}$ \\
\hline & Hospital[97] & & $\begin{array}{c}\text { Faraday cage measures the } \\
\text { amount of charge }\end{array}$ & \\
\hline $1980 \mathrm{~s} \sim 90 \mathrm{~s}$ & Saito[93]; & & Transmission electron microscope & $\begin{array}{c}\text { DC electric field strength, electrode shape } \\
\text { and position affect particle size and } \\
\text { concentration }\end{array}$ \\
\hline \multirow[t]{2}{*}{ Last ten years } & Maricq[94]; & $\begin{array}{c}\text { Charge number of soot } \\
\text { particles in flame }\end{array}$ & $\begin{array}{l}\text { Differential particle complement } \\
\text { analyzer; }\end{array}$ & $\begin{array}{c}\text { Different flame areas have different } \\
\text { charging characteristics of soot; }\end{array}$ \\
\hline & Katzer[95]; & Nanotubes & $\begin{array}{c}\text { Transmission electron } \\
\text { microscope; }\end{array}$ & $\begin{array}{c}\text { The nature and strength of the electric field } \\
\text { affect the size of nanoparticles; }\end{array}$ \\
\hline
\end{tabular}

\subsection{Current status of particulate matter diagnostic technology}

With the continuous improvement of the level of science and technology, the diagnostic technology of particulate matter has also developed from observing the particulate matter flying out of the flame collected through the filter with a microscope to being able to track the formation, agglomeration and movement of the particles [97]. The improvement of diagnostic technology is of great significance for studying the mechanism of the influence of the output of particulate matter in the flame under the electric field. The following will introduce several diagnostic techniques that are currently widely used.

\subsubsection{PIV-Particle Image Velocimetry}

The principle of PIV is to use a high-speed camera to capture a strong pulsed light source that illuminates the plane of the flow field. After the two pulses are 
irradiated, the camera will capture many particle pairs. Measuring the distance between a pair of particles and the time interval between two pulses can measure the speed of a single particle.

Jonathan et al. used PIV to observe the turbulent combustion flame of $\mathrm{CH}_{4}$ and air premixed [98]. The experiment observes the flame burning velocity field, from which the conditional average velocity in the reactant and product regions can be obtained. The results show that as the ratio of root mean square velocity to LBV increases, a transition from inverse gradient to gradient diffusion occurs.

\subsubsection{LII - Laser Induced Incandescence}

The principle of LII is to instantaneously heat the soot particles by a high-energy pulsed laser, and the soot particles will emit incandescent light with much greater intensity than the flame. Using the filter, the light of the soot particles can be observed and the volume concentration of the soot particles can be obtained. The volume concentration of soot particles can be used together with the detection results of other components as an important parameter to quantify the flame combustion characteristics. Kohse et al. summarized the development process of LII technology [99]. He concluded that the development of LII technology has been from the 1970s to the present, and the measured data has evolved from the simplest volume concentration to measuring the diameter and temperature of a single soot particle. The advancement of these technical observation methods provides important technical support for researchers to study the formation, growth, agglomeration and oxidation mechanisms of soot particles and the prediction of simulation results.

Lee et al. used LII to test the flame structure and soot characteristics of ethylene back diffusion flame (IDF) [100]. From the data detected by LII, the experiment estimated the influence of flow residence time and temperature on the generation of soot particles. It is also observed that the fuel dilution and the resulting temperature difference have a weaker effect on the soot particle generation time. As shown in the figure 10, the LII technology enables online real-time detection of important components in the flame combustion process, the concentration of hydroxyl, carbon monoxide, polycyclic aromatic hydrocarbons, and soot particles. In particular, the capture of intermediate products such as HCN that react quickly and disappear, makes targeted research possible. In addition, because the laser pulse interval used by LII is very short, some important components produced by turbulent flame combustion can be monitored in real time, which makes online diagnosis of turbulent flame possible. 


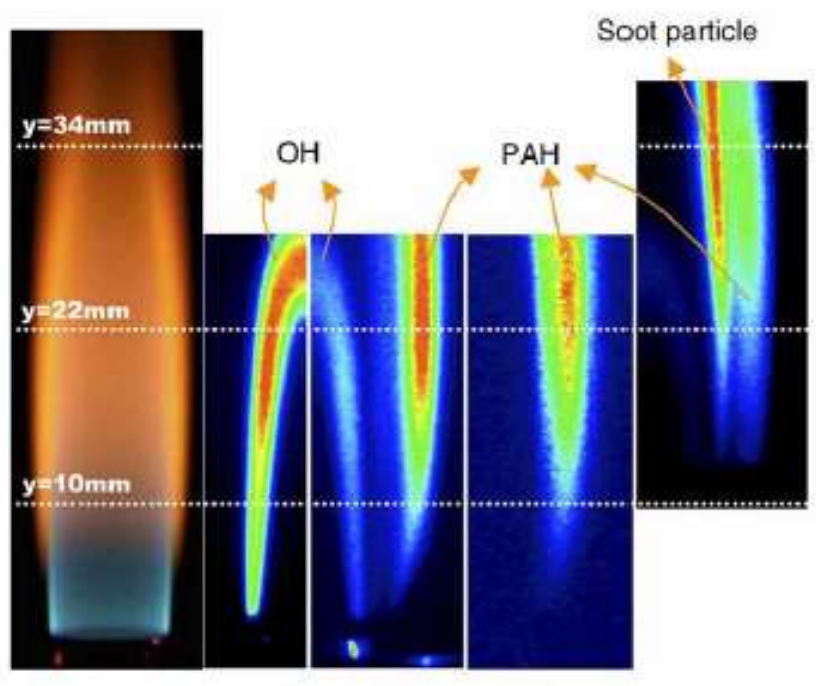

(a) (b)

(c)

(d)

Figure 10. Laser diagnosis of various components in the flame [100]

\subsubsection{PLIF -Planar Laser Induced Fluorescence}

The principle of PLIF is to emit a laser of a specific frequency to make it the same frequency as the electron transition from the ground state to the excited state. When the laser is irradiated, when the laser passes through the flame, reasonable resonance absorption can make the molecules of the measured substance escape from a certain electronic ground state under a certain electrical state. Since the energy level of the excited state is very high, there are almost no molecules in this state. Before resonance absorption, the total number of molecules in the elevated state in resonance absorption is proportional to the density of low-state molecules. When the electron returns to the ground state or low energy state, it will fluoresce. Using a high-speed camera to capture this fluorescence, the concentration distribution of the target substance can be obtained.

Jeffrey et al. used PLIF to observe the $\mathrm{CH}-\mathrm{OH}$ boundary in a non-premixed turbulent flame that can mark the sensitivity of instantaneous stoichiometry [101]. Experiments have found that $\mathrm{CH}$ and $\mathrm{OH}$ images can uniquely identify the fuel and air sides of the flame surface. Watson et al. used PLIF to measure the $\mathrm{CH}$ distribution of a methane-air premixed diffusion flame [102]. The experiment established the flow pattern that led to the complete rupture of the $\mathrm{CH}$ curve, and the study obtained the stable mechanism under the flow conditions. Han et al. used PLIF to observe the velocity field and $\mathrm{CH}$ distribution during the mixing and combustion process of the deflected jet flame at three different angles [103-104]. It is found that the $\mathrm{CH}$ distribution is consistent with the high strain rate region. Both the instantaneous and average $\mathrm{CH}$ distribution correspond well to the position of the stoichiometric velocity.

\subsubsection{TSPD-Thermophoretic Sampling Particles Diagnostics}


The principle of TSPD is that the phase of the transmission electron microscope sample is directly mounted on the probe, and the probe is driven by a two-dimensional lift valve. The relay is used to control the time when the probe enters and leaves the flame, so that real-time sampling can be achieved using a high-speed camera. The thermophoresis probe sampling method can obtain the instantaneous morphology of soot particles at a certain point in the flame, and because it is direct and instantaneous sampling, researchers can observe the instantaneous morphology of soot particles and agglomerates. . Currently, the TSPD method has been used as a standard measurement method in conjunction with the LII method. Kock et al. used TSPD to observe the size of the iron particle chain during the synthesis process and compared it with the observation result of LII [105]. The experiment found that the particle size determined by LII is very consistent with the primary particle size measured by TEM.

Lee et al. used TSPD and PLIF to monitor the synergy of polycyclic aromatic hydrocarbons $(\mathrm{PAH})$ and soot in the ethylene-propane diffusion flame in real time [106]. The experiment observed that the larger size of PAH has a stronger synergistic effect.

Oh et al. used TSPD and LII to observe the evolution of soot particles in the ethylene-air reverse flame [107]. Experiments have observed that soot particles develop along the flame front, undergoing particle size growth, agglomeration of aggregates and carbonaceous processes, and the soot volume fraction depends on the initial rate. Later, Oh et al. directly sampled soot through TSPD, and studied the influence of oxygen concentration on the oxidant side and carbon dioxide as a diluent on soot formation [108]. It was observed that the soot volume fraction was inhibited. The inhibition is due to the short residence time in the later stage of nucleation. Due to the higher heat capacity and the chemical change of carbon dioxide, the surface growth distance decreases due to the decrease of flame temperature, and the residence time in the initial region is also greatly reduced.

\subsection{Influence of DC electric field on soot particles}

Saito et al. found in experiments that the addition of a DC electric field can greatly reduce the amount of soot emissions, and the effect of a positive DC electric field will be better than that of a negative DC electric field in suppressing soot [109]. A positive DC electric field can reduce soot emissions by $90 \%$, and a negative DC electric field can reduce soot emissions by $70 \%$. Saito's explanation for this is: first, the ion wind effect accelerates the mixing of fuel and oxidant, making the reaction more complete; second, the positive electric field makes the generally positively charged soot particles fly into the high temperature faster from the formation zone at the bottom of the flame Reaction zone, so that the soot particles are fully oxidized by the oxidant before they grow up.

Saito et al. also found [6] that the addition of a DC electric field makes the average flame temperature higher than $2000^{\circ} \mathrm{C}$. The temperature at which the soot particles are formed is between 1000 and $1800^{\circ} \mathrm{C}$, indicating that the full oxidation of soot particles increases the temperature of the flame, and the increased temperature in 
turn increases the average temperature of the flame. The high flame temperature inhibits the new The formation of soot particles.

Katzer et al. studied the effect of applying an electric field on the preparation of $\mathrm{TiO}_{2}$ [9]. The experiment summarized three important conclusions about the influence of electric field on particles. 1. The ionic wind effect produced by the external direct current field makes the particles of different charges in the flame fully react. 2 . The force generated by the ion wind effect causes the flame to move toward the electrodes on both sides, and the flame center temperature decreases. 3 . The decrease in the temperature of the central flame makes the agglomeration of particles obvious, and the size of the particles increases.

\subsection{Effect of AC electric field on soot particles}

Unlike the DC electric field, the polarity of the AC electrode changes with its own frequency, and the ion wind formed is not continuous, but instead depends on the free diffusion of charged particles and electrons to achieve the change in charge distribution. Such characteristics cause the particle characteristics under the influence of AC electric field to be somewhat different from the influence of direct current. Research by Ohisa et al. found that the AC electric field can also effectively reduce the emission of soot particles [110]. Different from the influence of the DC electric field, the AC current has a cut-off value, that is, when the voltage increases to a certain value, the medium will break down, produce arc discharge, and the current will be cut off. as the figure 11 shows. Another difference is that the distance between the two discharged electrodes in the DC electric field and the AC electric field has completely opposite effects on the soot particles. When the electrode distance is relatively large, the suppression effect of the DC electric field on the soot particles is better, but the suppression effect of the AC electric field can be better displayed when the two electrodes are close together. The author has not made a corresponding explanation on this point, and the specific reasons need to be further explored.

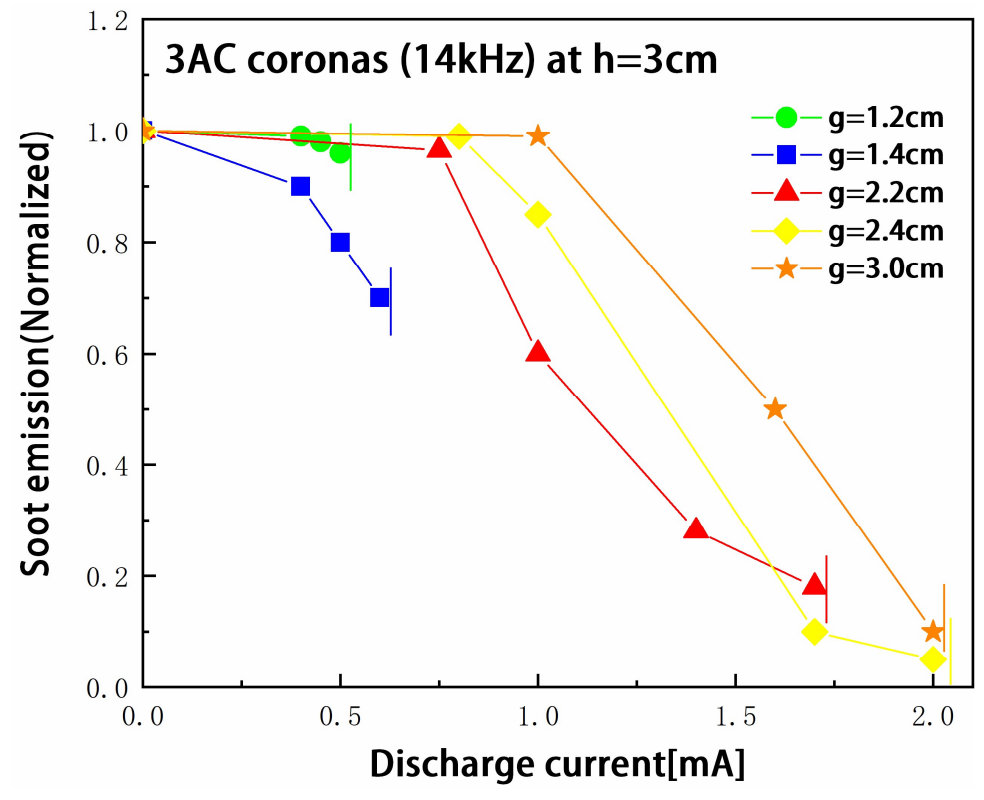


Figure 11. Changes in the mass concentration of soot particles in an AC electric field with current [110]

The difference between the influence of DC electric field and AC electric field on soot particles is also reflected in the number of ions in the flame [111]. The ion concentration in the DC electric field is nearly 10 times higher than that in the AC electric field, indicating that the continuous ion wind generated by the DC electric field will significantly increase the number of charged particles at a similar electric field strength. This phenomenon makes the matter in the flame faster The mixing and reaction.

Although the diagnostic technology of particles has been greatly improved compared with the past, there are still certain problems. First of all, the detection technology needs to be improved. At this stage, it is not possible to accurately measure the charged amount of soot particles. Secondly, the relationship between the size and morphology of nano-scale soot aggregates and aggregates and the electrostatic force between particles needs to be studied in depth. Finally, the simulation technology needs to be more researched, and the corresponding relationship between the characteristics of the soot particles at each growth stage and the charging capacity needs to be studied in depth.

\section{Conclusion}

This article summarizes the current research on the influence of electric fields on flame combustion. It can be seen from the above analysis that it has become possible to use electric fields to enhance the flame combustion rate and control the flame combustion characteristics, thereby increasing the energy conversion efficiency and reducing the emission of polluting combustion products. However, no one has carried out systematic research on different electric field forms and combustion flame characteristics. There is a lack of corresponding basic data, a combustion reaction kinetic model with electric field participation, a complete analysis of the coupling mechanism of electric field and combustion field, and the flame characteristics of solid phase fuel under electric field., Magnetic field, sound field, gravitational field, combustion field and other multi-field coupling research.

Some scholars have studied the changing laws of the combustion flame characteristics of various fuels put into it by changing the form and parameters of the electric field. The conclusions drawn in this article are as follows:

(1) Bidirectional ion wind effect, aerodynamic effect and electrochemical reaction are the main reasons for electric field assisted combustion. But the two-way ion wind mainly explains the stagnant flame. As for the influence of the flame in the propagation process, more research is needed to find a more reasonable explanation.

(2) The simulation of flame is mostly concentrated in one-dimensional and two-dimensional. Due to the high development cost and too many factors, few people can build the three-dimensional model. Further research is needed for the development of the model. 
(3) The distribution of the electric field and the application form of the electric field will have different effects on the flame. The DC electric field has a smaller effect than the AC electric field. The ion wind effect produced by the negative electric field is more obvious, and the positive electric field can better promote the flame combustion. The combustion-supporting effect of high-frequency electric field is better than that of low-frequency electric field.

(4) The application of AC and DC electric fields can reduce the emission of soot particles, and the effect of the positive DC electric field is better. Particle diagnosis technology needs to be further developed to obtain more accurate values and observe more subtle changes.

\section{Acknowledgement}

This work was supported by the Jiangsu Basic Research Project (Natural Science Fund; number BK20180982).

\section{References}

[1] Y.C. Hong, H.S. Uhm, Properties of plasma flames sustained by microwaves and burning hydrocarbon fuels, Physics of Plasmas 13(11) (2006).

[2] K.W. Hemawan, C.L. Romel, S. Zuo, I.S. Wichman, T.A. Grotjohn, J. Asmussen, Microwave plasma-assisted premixed flame combustion, Applied Physics Letters 89(14) (2006).

[3] C. Kong, Z. Li, M. Aldén, A. Ehn, Stabilization of a turbulent premixed flame by a plasma filament, Combustion and Flame 208 (2019) 79-85.

[4] Hartwell F. Calcote, Electrical properties of flames burner flames in transverse electric fields,flame propagation in explosive gas mixtures(1951)245-253.

[5] K.G. Xu, Plasma sheath behavior and ionic wind effect in electric field modified flames, Combustion and Flame 161(6) (2014) 1678-1686.

[6] D.G. Park, S.H. Chung, M.S. Cha, Bidirectional ionic wind in nonpremixed counterflow flames with DC electric fields, Combustion and Flame 168 (2016) 138-146.

[7] YC. Chien, D. Escofet-Martin, D. Dunn-Rankin, Ion current and carbon monoxide release from an impinging methane/air coflow flame in an electric field, Combustion and Flame 204 (2019) 250-259.

[8] P. Gillon, V. Gilard, M. Idir, B. Sarh, Electric field influence on the stability and the soot particles emission of a laminar diffusion flame, Combustion Science and Technology 191(2) (2018) 325-338.

[9] S. Marcum, B. Ganguly, Electric-field-induced flame speed modification, Combustion and Flame 143(1-2) (2005) 27-36.

[10] Y. Luo, Y. Gan, X. Jiang, Investigation of the effect of DC electric field on a small ethanol diffusion flame, Fuel 188 (2017) 621-627.

[11] S.H. Yoon, B. Seo, J. Park, S.H. Chung, M.S. Cha, Edge flame propagation via parallel electric fields in nonpremixed coflow jets, Proceedings of the 
Combustion Institute 37(4) (2019) 5537-5544.

[12] F. Altendorfner, J. Kuhl, L. Zigan, A. Leipertz, Study of the influence of electric fields on flames using planar LIF and PIV techniques, Proceedings of the Combustion Institute 33(2) (2011) 3195-3201.

[13] Y. Wang, G.J. Nathan, Z.T. Alwahabi, K.D. King, K. Ho, Q. Yao, Effect of a uniform electric field on soot in laminar premixed ethylene/air flames, Combustion and Flame 157(7) (2010) 1308-1315.

[14] Y. Zhang, Y. Li, P. Liu, R. Zhan, Z. Huang, H. Lin, Investigation on the chemical effects of dimethyl ether and ethanol additions on PAH formation in laminar premixed ethylene flames, Fuel 256 (2019).

[15] YC. Chien, D. Dunn-Rankin, Electric Field Induced Changes of a Diffusion Flame and Heat Transfer near an Impinging Surface, Energies 11(5) (2018).

[16] Y.C. Chien, D. Escofet-Martin, D. Dunn-Rankin, CO Emission from an Impinging Non-Premixed Flame, Combust Flame 174 (2016) 16-24.

[17] F.J. Weinberg, D. Dunn-Rankin, F.B. Carleton, S. Karnani, C. Markides, M. Zhai, Electrical aspects of flame quenching, Proceedings of the Combustion Institute 34(2) (2013) 3295-3301.

[18] M. Di Renzo, J. Urzay, P. De Palma, M.D. de Tullio, G. Pascazio, The effects of incident electric fields on counterflow diffusion flames, Combustion and Flame 193 (2018) 177-191.

[19] D.C. Murphy, M. Sánchez-Sanz, C. Fernandez-Pello, An experimental and numerical study of flames in narrow channels with electric fields, Journal of Physics: Conference Series 557 (2014).

[20] M.V. Tran, M.S. Cha, Correction of edge-flame propagation speed in a counterflow, annular slot burner, Combustion and Flame 162(12) (2015) 4671-4672.

[21] M.-V. Tran, M.S. Cha, Time evolution of propagating nonpremixed flames in a counterflow, annular slot burner under AC electric fields, Proceedings of the Combustion Institute 36(1) (2017) 1421-1430.

[22] S.H. Chung, Stabilization, propagation and instability of tribrachial triple flames, Proceedings of the Combustion Institute 31(1) (2007) 877-892.

[23] M.-V. Tran, M.S. Cha, Propagating nonpremixed edge-flames in a counterflow, annular slot burner under DC electric fields, Combustion and Flame 173 (2016) 114-122.

[24] J. Wang, Y. Li, H. Xia, R. Ju, M. Zhang, H. Mu, Z. Huang, Effect of hydrogen enrichment and electric field on lean $\mathrm{CH} 4$ /air flame propagation at elevated pressure, International Journal of Hydrogen Energy 44(30) (2019) 15962-15972.

[25] C. Li, X. Wu, Y. Li, X. Wei, Experimental study of positive and negative DC electric fields in lean premixed spherically expanding flames, Fuel 193 (2017) 22-30.

[26] J. Fang, X. Wu, H. Duan, C. Li, Z. Gao, Effects of Electric Fields on the Combustion Characteristics of Lean Burn Methane-Air Mixtures, Energies 8(4) (2015) 2587-2605. 
[27] H. Duan, X. Wu, J. Hou, C. Zhang, Z. Gao, Experimental study of lean premixed $\mathrm{CH} 4 / \mathrm{N} 2 / \mathrm{O} 2$ flames under low-frequency alternating-current electric fields, Fuel 181 (2016) 1011-1019.

[28] A.A. Konnov, I.V. Dyakov, J. De Ruyck, Probe Sampling Measurements and Modeling of Nitric Oxide Formation in Methane-Air Flames, Combustion Science and Technology 169(1) (2001) 127-153.

[29] I.V. Dyakov, A.A. Konnov, J.D. Ruyck, K.J. Bosschaart, E.C.M. Brock, L.P.H. De Goey, Measurement of Adiabatic Burning Velocity in Methane-Oxygen-Nitrogen Mixtures, Combustion Science and Technology 172(1) (2001) 81-96.

[30] J.D.B.J. van den Boom, A.A. Konnov, A.M.H.H. Verhasselt, V.N. Kornilov, L.P.H. de Goey, H. Nijmeijer, The effect of a DC electric field on the laminar burning velocity of premixed methane/air flames, Proceedings of the Combustion Institute 32(1) (2009) 1237-1244.

[31] K G Xu,Plasma sheath behavior and ionic wind effect in electric field modified Flames,Combustion and Flame 161 (2014) 1678 - 1686.

[32] H. Qin, S. Liang, L. Chen, Y. Li, Z. Luo, S. Chen, Recent advances in vanadium-based nanomaterials and their composites for supercapacitors, Sustainable Energy \& Fuels (2020).

[33] L. Vejby-Christensen,L.H. Andersen, O. Heber, D. Kella, H. B. Pedersen,H. T. Schmidt, And D. Zajfman,Complete branching ratios for the dissociative recombination of $\mathrm{H}_{2} \mathrm{O}^{+}$, and $\mathrm{H}_{3} \mathrm{O}^{+}, \mathrm{CH}_{3}{ }^{+}$

[34] D. Kim, F. Rizzi, K.W. Cheng, J. Han, F. Bisetti, O.M. Knio, Uncertainty quantification of ion chemistry in lean and stoichiometric homogenous mixtures of methane, oxygen, and argon, Combustion and Flame 162(7) (2015) 2904-2915.

[35] K. Yamashita, S. Karnani, D. Dunn-Rankin, Numerical prediction of ion current from a small methane jet flame, Combustion and Flame 156(6) (2009) 1227-1233.

[36] Ya. B. Zeldovich, G. I. Barenblatt, V. B. Librovich, and G. M. Makhviladze, The Mathematical Theory of Combustion and Explosions, combustion and flame 67(1987)185-186

[37] J. W. Dold, R. W. Thatcher, A. Omon-Arancibia and J. Redman,From one-step to chain-branching premixed flame asymptotics,Proceedings of the Combustion Institute 29 (2002) 1519 - 1526.

[38] J.W. Dold, Premixed flames modelled with thermally sensitive intermediate branching kinetics, Combustion Theory and Modelling 11(6) (2007) 909-948.

[39] G.J. Sharpe, Thermal-Diffusive Instability of Premixed Flames for a Simple Chain-Branching Chemistry Model with Finite Activation Energy, SIAM Journal on Applied Mathematics 70(3) (2009) 866-884.

[40] M. Sánchez-Sanz, D.C. Murphy, C. Fernandez-Pello, Effect of an external electric field on the propagation velocity of premixed flames, Proceedings of the Combustion Institute 35(3) (2015) 3463-3470.

[41] H. F. Calcote, S. C. Kurzius, and W. J. Miller,Negative and secondary ion 
formation in low-pressure flames, Tenth Symposium (International) on Combustion, (1965) 605-619.

[42] M.J. Papac, D. Dunn-Rankin, Modelling electric field driven convection in small combustion plasmas and surrounding gases, Combustion Theory and Modelling 12(1) (2007) 23-44.

[43] M. Belhi, P. Domingo, P. Vervisch, Direct numerical simulation of the effect of an electric field on flame stability, Combustion and Flame 157(12) (2010) 2286-2297.

[44] J Hu, B Rivin, E Sher, The effect of an electric field on the shape of co-flowing and candle-type methane-air flames,Experimental Thermal and Fluid Science 21 (2000) 124-133.

[45] M.J. Papac, D. Dunn-Rankin, Modelling electric field driven convection in small combustion plasmas and surrounding gases, Combustion Theory and Modelling 12(1) (2007) 23-44.

[46] M. Belhi, P. Domingo, P. Vervisch, Direct numerical simulation of the effect of an electric field on flame stability, Combustion and Flame 157(12) (2010) 2286-2297.

[47] N. Speelman, L.P.H. de Goey, J.A. van Oijen, Development of a numerical model for the electric current in burner-stabilised methane-air flames, Combustion Theory and Modelling 19(2) (2015) 159-187.

[48] M Belhi, BJ Lee, F Bisetti,H G. Im,A computational study of the effects of DC electric fields on non-premixed counterflow methane-air flames, Journal of Physics D: Applied Physics (2017)

[49] M. Belhi, P. Domingo, P. Vervisch, Modelling of the effect of DC and AC electric fields on the stability of a lifted diffusion methane/air flame, Combustion Theory and Modelling 17(4) (2013) 749-787.

[50] M. Di Renzo, P. De Palma, M.D. de Tullio, G. Pascazio, An efficient flamelet progress-variable method for modeling non-premixed flames in weak electric fields, Computers \& Fluids 157 (2017) 14-27.

[51] M. Belhi, B.J. Lee, M.S. Cha, H.G. Im, Three-dimensional simulation of ionic wind in a laminar premixed Bunsen flame subjected to a transverse DC electric field, Combustion and Flame 202 (2019) 90-106.

[52] D.G. Park, S.H. Chung, M.S. Cha, Visualization of ionic wind in laminar jet flames, Combustion and Flame 184 (2017) 246-248.

[53] J. Han, M. Belhi, F. Bisetti, S. Mani Sarathy, Numerical modelling of ion transport in flames, Combustion Theory and Modelling 19(6) (2015) 744-772.

[54] Y. Ren, W. Cui, H. Pitsch, S. Li, Experimental and numerical studies on electric field distribution of a premixed stagnation flame under DC power supply, Combustion and Flame 215 (2020) 103-112.

[55] O. Imamura, Y. Kubo, J. Osaka, J.i. Sato, M. Tsue, M. Kono, A study on single fuel droplets combustion in vertical direct current electric fields, Proceedings of the Combustion Institute 30(2) (2005) 1949-1956.

[56] T. Ueda, O. Imamura, K. Okai, M. Tsue, M. Kono and J. Sato,Combustion behavior of single droplets for sooting and non-sooting fuels in direct current 
electric fields under microgravity,Proceedings of the Combustion Institute 29(2002) 2595 - 2601.

[57] S. Okajima,Experimental studies on combustion of fuel droplets in flowing air under zero- and high-gravity conditions,Nineteenth Symposium (International) on Combustion/The Combustion Institute (1982)1021-1027.

[58] O. Imamura, B. Chen, S. Nishida, K. Yamashita, M. Tsue, M. Kono, Combustion of ethanol fuel droplet in vertical direct current electric field, Proceedings of the Combustion Institute 33(2) (2011) 2005-2011.

[59] M. Cha, S. Lee, K. Kim, S. Chung, Soot suppression by nonthermal plasma in coflow jet diffusion flames using a dielectric barrier discharge, Combustion and Flame 141(4) (2005) 438-447.

[60] Y. Li, J. Wang, H. Xia, C. Li, M. Zhang, X. Wu, Z. Huang, H. Mu, Effect of DC electric field on laminar premixed spherical propagation flame at elevated pressures up to 0.5 MPa, Combustion Science and Technology 190(11) (2018) 1900-1922.

[61] X. Meng, X. Wu, C. Kang, A. Tang, Z. Gao, Effects of Direct-Current (DC) Electric Fields on Flame Propagation and Combustion Characteristics of Premixed CH4/O2/N2 Flames, Energy \& Fuels 26(11) (2012) 6612-6620.

[62] S.K. Ryu, Y.K. Kim, M.K. Kim, S.H. Won, S.H. Chung, Observation of multi-scale oscillation of laminar lifted flames with low-frequency AC electric fields, Combustion and Flame 157(1) (2010) 25-32.

[63] M.K. Kim, S.K. Ryu, S.H. Won, S.H. Chung, Electric fields effect on liftoff and blowoff of nonpremixed laminar jet flames in a coflow, Combustion and Flame 157(1) (2010) 17-24.

[64] Q. Bao, C. Pan, Electric field induced growth of well aligned carbon nanotubes from ethanol flames, Nanotechnology 17(4) (2006) 1016-21.

[65] K. Masunaga, H. Ito, O. Fujita, Investigation of applying DC electric field effect on carbon nanotube synthesis, Asia-Pacific Journal of Chemical Engineering 8(2) (2013) 246-253.

[66] S.H. Won, M.S. Cha, C.S. Park, S.H. Chung, Effect of electric fields on reattachment and propagation speed of tribrachial flames in laminar coflow jets, Proceedings of the Combustion Institute 31(1) (2007) 963-970.

[67] Guo Li, Zhai Ming, Zhang YiChi \& Dong Peng,Electrical characteristics of laminar propane flame during head-on quenching,Technological Sciences 63 (2020)1497 - 1508 .

[68] J. Prager, U. Riedel, J. Warnatz, Modeling ion chemistry and charged species diffusion in lean methane - oxygen flames, Proceedings of the Combustion Institute 31(1) (2007) 1129-1137.

[69] Y. Gan, M. Wang, Y. Luo, X. Chen, J. Xu, Effects of direct-current electric fields on flame shape and combustion characteristics of ethanol in small scale, Advances in Mechanical Engineering 8(1) (2016).

[70] M. Simeni Simeni, Y. Tang, Y.-C. Hung, Z. Eckert, K. Frederickson, I.V. Adamovich, Electric field in Ns pulse and AC electric discharges in a hydrogen diffusion flame, Combustion and Flame 197 (2018) 254-264. 
[71] A. Ata, J.S. Cowart, A. Vranos, B.M. Cetegen, Effects of Direct Current Electric Field on the Blowoff Characteristics of Bluff-Body Stabilized Conical Premixed Flames, Combustion Science and Technology 177(7) (2005) 1291-1304.

[72] H.S. Zhen, Z.W. Wang, X.Y. Liu, Z.L. Wei, Z.H. Huang, C.W. Leung, An experimental study on the effect of DC electric field on impinging flame, Fuel 274 (2020).

[73] Y. Luo, Y. Gan, J. Xu, Y. Yan, Y. Shi, Effects of electric field intensity and frequency of AC electric field on the small-scale ethanol diffusion flame behaviors, Applied Thermal Engineering 115 (2017) 1330-1336.

[74] Y. Zhang, Y. Wu, H. Yang, H. Zhang, M. Zhu, Effect of high-frequency alternating electric fields on the behavior and nitric oxide emission of laminar non-premixed flames, Fuel 109 (2013) 350-355.

[75] E.V. Vega, S.S. Shin, K.Y. Lee, NO emission of oxygen-enriched CH4/O2/N2 premixed flames under electric field, Fuel 86(4) (2007) 512-519.

[76] A. Sakhrieh, G. Lins, F. Dinkelacker, T. Hammer, A. Leipertz, D.W. Branston, The influence of pressure on the control of premixed turbulent flames using an electric field, Combustion and Flame 143(3) (2005) 313-322.

[77] S.H. Park, S.J. Lim, M.S. Cha, J. Park, S.H. Chung, Effect of AC electric field on flame spread in electrical wire: Variation in polyethylene insulation thickness and di-electrophoresis phenomenon, Combustion and Flame 202 (2019) 107-118.

[78] Y. Ren, S. Li, W. Cui, Y. Zhang, L. Ma, Low-frequency AC electric field induced thermoacoustic oscillation of a premixed stagnation flame, Combustion and Flame 176 (2017) 479-488.

[79] M.K. Kim, S.H. Chung, O. Fujita, Effect of AC electric fields on flame spread over electrical wire, Proceedings of the Combustion Institute 33(1) (2011) $1145-1151$.

[80] D.G. Park, S.H. Chung, M.S. Cha, Dynamic responses of counterflow nonpremixed flames to AC electric field, Combustion and Flame 198 (2018) 240-248.

[81] S.J. Lim, S.H. Park, J. Park, O. Fujita, S.I. Keel, S.H. Chung, Flame spread over inclined electrical wires with AC electric fields, Combustion and Flame 185 (2017) 82-92.

[82] M.K. Kim, S.H. Chung, H.H. Kim, Effect of AC electric fields on the stabilization of premixed bunsen flames, Proceedings of the Combustion Institute 33(1) (2011) 1137-1144.

[83] M.K. Kim, S.H. Chung, H.H. Kim, Effect of electric fields on the stabilization of premixed laminar bunsen flames at low AC frequency: Bi-ionic wind effect, Combustion and Flame 159(3) (2012) 1151-1159.

[84] P. K. Tretyakov, A. V. Tupikin and V. N. Zudov,Effect of Laser Radiation and Electric Field on Combustion of Hydrocarbon - Air Mixtures,Combustion, Explosion, and Shock Waves 45( 2009)413 - 420.

[85] H. Duan, X. Wu, T. Sun, B. Liu, J. Fang, C. Li, Z. Gao, Effects of electric field 
intensity and distribution on flame propagation speed of $\mathrm{CH} 4 / \mathrm{O} 2 / \mathrm{N} 2$ flames, Fuel 158 (2015) 807-815.

[86] J. Kuhl, G. Jovicic, L. Zigan, S. Will, A. Leipertz, Influence of electric fields on premixed laminar flames: Visualization of perturbations and potential for suppression of thermoacoustic oscillations, Proceedings of the Combustion Institute 35(3) (2015) 3521-3528.

[87] J. Kuhl, T. Seeger, L. Zigan, S. Will, A. Leipertz, On the effect of ionic wind on structure and temperature of laminar premixed flames influenced by electric fields, Combustion and Flame 176 (2017) 391-399.

[88] Sugden, T. M., and Thrush, B. A., Nature 168(1951)703-704.

[89] F. Weinberg, F. Carleton, D. Dunn-Rankin, Electric field-controlled mesoscale burners, Combustion and Flame 152(1-2) (2008) 186-193.

[90] H. F. Calcote,Mechanisms of Soot Nucleation in Flames-A Critical Review.Combustion and Flame 42 ( 1981)215- 242.

[91] V. Sick, A. Arnold, E. DIEIbEL, T. DREIER, W. Ke'iterle, B. Lange, J. wolfrum, Two-dimensional laser diagnostics and modeling of counterflow diffusion flames, Twenty-Third Symposium (International) on Combustion/The Combustion Institute (1990) 495-501.

[92] M. Kono, The effect of nonsteady electric fields on sooting flames,combustion and flame 78(1989)357-364.

[93] Masahiro Saito, Masayuki Sato, Katsuhiro Sawada,Variation of flame shape and soot emission by applying electric field,Journal of Electrostatics 39 (1997) 305-311.

[94] M.M. Maricq, S.J. Harris, J.J. Szente, Soot size distributions in rich premixed ethylene flames, Combustion and Flame 132(3) (2003) 328-342.

[95] M. Katzer, A. P. Weber, G. Kasper,The effects of electrical fields on growth of titania particles formed in a CH4-O2 diffusion flame,Aerosol Science 32 (2001) 1045-1067.

[96] M. Zake, D. Turlajs, M. Purmals,Electric field control of nox formation in the flame channel flows, Global Nest: the Int. J. 2(2000) 99-108.

[97] M. Balthasar and F. Mauss,A Computational Study of the Thermal Ionization of Soot Particles and Its Effect on their Growth in Laminar Premixed Flames,combustion and flame 129(2002)204-216.

[98] Jonathan H. Frank, Peter A. M. Kalt, and Robert W. Bilger,Measurements of Conditional Velocities in Turbulent Premixed Flames by Simultaneous $\mathrm{OH}$ PLIF and PIV.combustion and flame 116 (1999)220 - 232.

[99] Katharina Kohse-Hoinghaus and Jay B. Jeffries,Applied Combustion Diagnostics,Combustion and Flame 133 (2003) 507 - 508.

[100] E. Lee, K. Oh, H. Shin, Soot formation in inverse diffusion flames of diluted ethene, Fuel 84(5) (2005) 543-550.

[101] Jeffrey M. Donbar and James F. Driscoll,Reaction Zone Structure in Turbulent Nonpremixed Jet Flames-From CH-OH PLIF Images,combustion and flame 122(2000)1 - 19 .

[102] K. A. Watson and K. M. Lyons,Simultaneous Rayleigh Imaging and CH-PLIF 
Measurements in a Lifted Jet Diffusion Flame,combustion and flame 123(2000)252- 265.

[103] D. Han, M.G. Mungal, Simultaneous measurements of velocity and CH distributions. Part 1: jet flames in co-flow, Combustion and Flame 132(3) (2003) 565-590.

[104] D. Han, M.G. Mungal, Simultaneous measurements of velocity and CH distribution. Part II: deflected jet flames, Combustion and Flame 133(1-2) (2003) 1-17.

[105] B.F. Kock, C. Kayan, J. Knipping, H.R. Orthner, P. Roth, Comparison of LII and TEM sizing during synthesis of iron particle chains, Proceedings of the Combustion Institute 30(1) (2005) 1689-1697.

[106] S.M. Lee, S.S. Yoon, S.H. Chung, Synergistic effect on soot formation in counterflow diffusion flames of ethylene-propane mixtures with benzene addition, Combustion and Flame 136(4) (2004) 493-500.

[107] K. Oh, U. Lee, H. Shin, E. Lee, The evolution of incipient soot particles in an inverse diffusion flame of ethene, Combustion and Flame 140(3) (2005) 249-254.

[108] K. Oh, H. Shin, The effect of oxygen and carbon dioxide concentration on soot formation in non-premixed flames, Fuel 85(5-6) (2006) 615-624.

[109] Masahiro Saito, Toshihiro Arai, and Masataka Arai,Control of Soot Emitted from Acetylene Diffusion Flames by Applying an Electric Field,combustion and flame 119(1999)356 - 366 .

[110] H Ohisa, I Kimura, and H Horisawa,Control of Soot Emission of a Turbulent Diffusion Flame by DC or AC Corona Discharges,combustion and flame 116:653 - 661 (1999).

[111] M. Yen, V. Magi, J. Abraham, Modeling the effects of hydrogen and nitrogen addition on soot formation in laminar ethylene jet diffusion flames, Chemical Engineering Science 196 (2019) 116-129. 